Portland State University

PDXScholar

$5-14-1976$

\title{
Assessment of Hearing Sensitivity by Use of the Acoustic Reflex in the Geriatric Population
}

Donna Elvira Gilham

Portland State University

Follow this and additional works at: https://pdxscholar.library.pdx.edu/open_access_etds

Part of the Speech and Hearing Science Commons, and the Speech Pathology and Audiology Commons

Let us know how access to this document benefits you.

\section{Recommended Citation}

Gilham, Donna Elvira, "Assessment of Hearing Sensitivity by Use of the Acoustic Reflex in the Geriatric Population" (1976). Dissertations and Theses. Paper 2284.

https://doi.org/10.15760/etd.2281

This Thesis is brought to you for free and open access. It has been accepted for inclusion in Dissertations and Theses by an authorized administrator of PDXScholar. Please contact us if we can make this document more accessible: pdxscholar@pdx.edu. 
AN ABSTRACT OF THE THESIS OF Donna Elvira Gilham for the Master of Science in Speech Communication with major emphasis in Audiology and Speech Pathology presented May 14, 1976.

Title: Assessment of Hearing Sensitivity by Use of the Acoustic Reflex in the Geriatric Population.

APPROVED BY MEMBERS OF THE THESIS COMMITTEE:
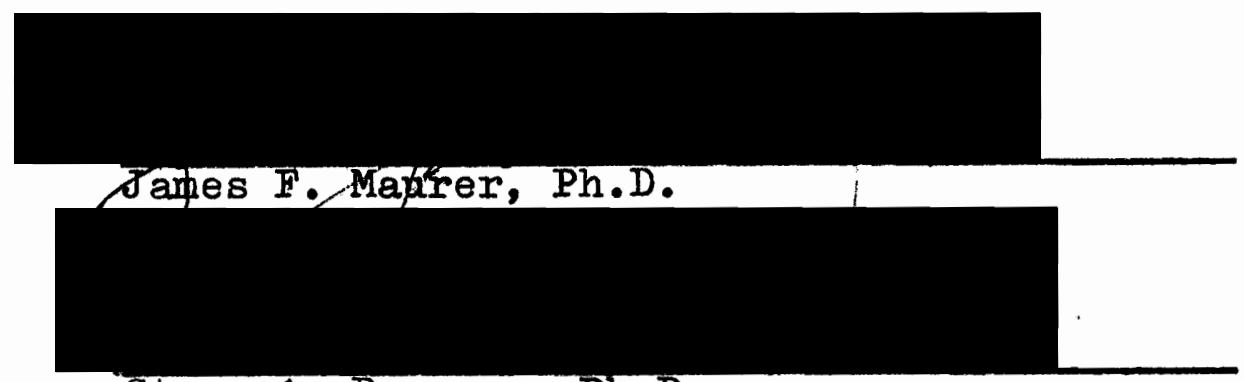

Steve A. Brannan, Ph.D.

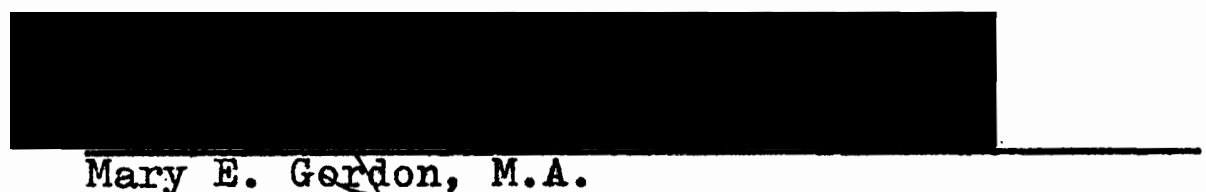

The purpose of this study was to investigate the use of the SPAR test (Sensitivity Prediction by the Acoustic Reflex) on a sample of older adults who professed negative otologic histories. Twenty-seven subjects, ranging in age from sixty-four to eighty-three years of age (54 ears) were ultimately chosen as subjects. A young adult group, ranging 
in age from eighteen to thirty years of age, with normal audiometric hearing levels served as controls. Reflex threshold levels were obtained using $500 \mathrm{~Hz}, 1000 \mathrm{~Hz}$., and $2000 \mathrm{~Hz}$. pure tones and noise stimuli. Assessment of hearing loss was calculated on the difference between measures to ascertain hearing loss category and slope of Ioss according to a formula developed by Jerger (1974). The following conclusions were made on the basis of data collected in this investigation:

1) The SPAR test was significant in assessing hearing sensitivity levels among the sample of geriatric subjects.

2) The SPAR test was not statistically significant in assessing slope of loss in this sample of geriatric subjects.

3) Reflex thresholds were consistently higher for aging than for a sample of young adults with normal hearing. This was true even among elderly subjects with average pure tone thresholds in the normal range.

4) A significant portion of this carefully screened older adult sample displayed abnormal middle-ear function (as measured by tympanometry) in the absence of conventional audiometric indications of this.

5) A significant portion of this older adult sample provided audiometric evidence of middle-ear pathology. 


\title{
ASSESSMENT OF HEARING SENSITIVITY \\ BY USE OF THE ACOUSTIC REFLEX \\ IN THE GERIATRIC POPULATION
}

\author{
by \\ DONNA E. GILHAM
}

A thesis submitted in partial fulfillment of the requirements for the degree of

\author{
MASTER OF SCIENCE \\ in \\ SPEECH COMMUNICATION \\ with emphasis in Audiology \\ and Speech Pathology.
}

Portland State University

1976 
TO THE OFFICE OF GRADUATE STUDIES AND RESEARCH:

The members of the Committee approve the thesis of Donna Elvira Gilham presented May 14, 1976.

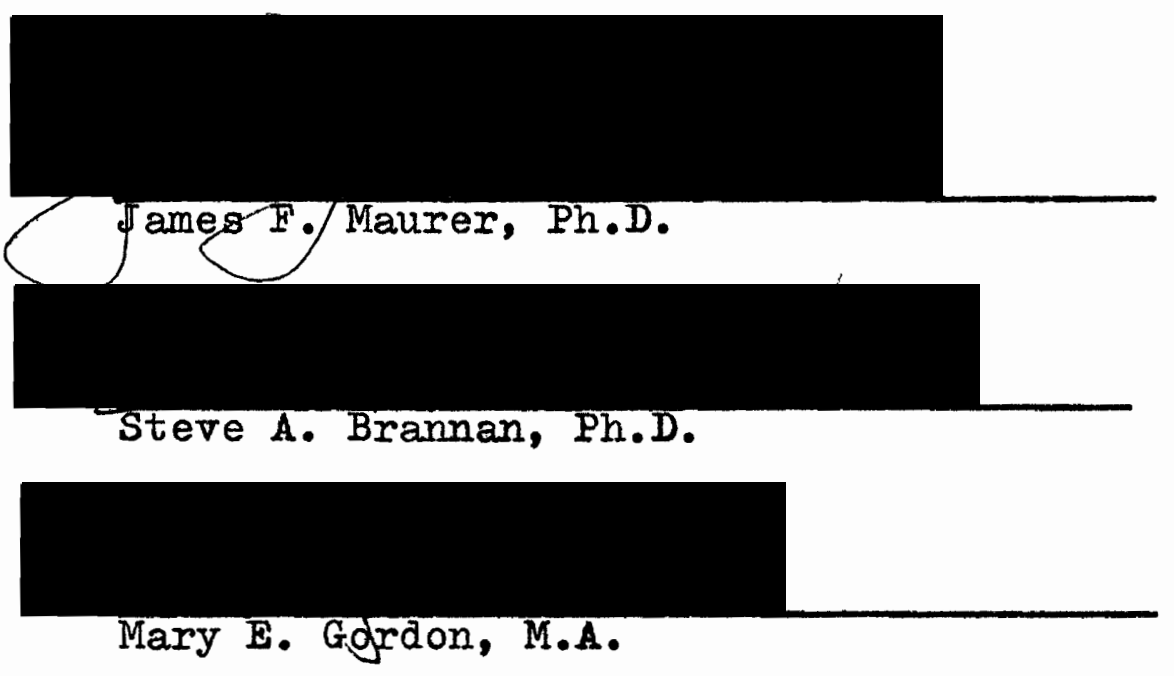

APPROVED:

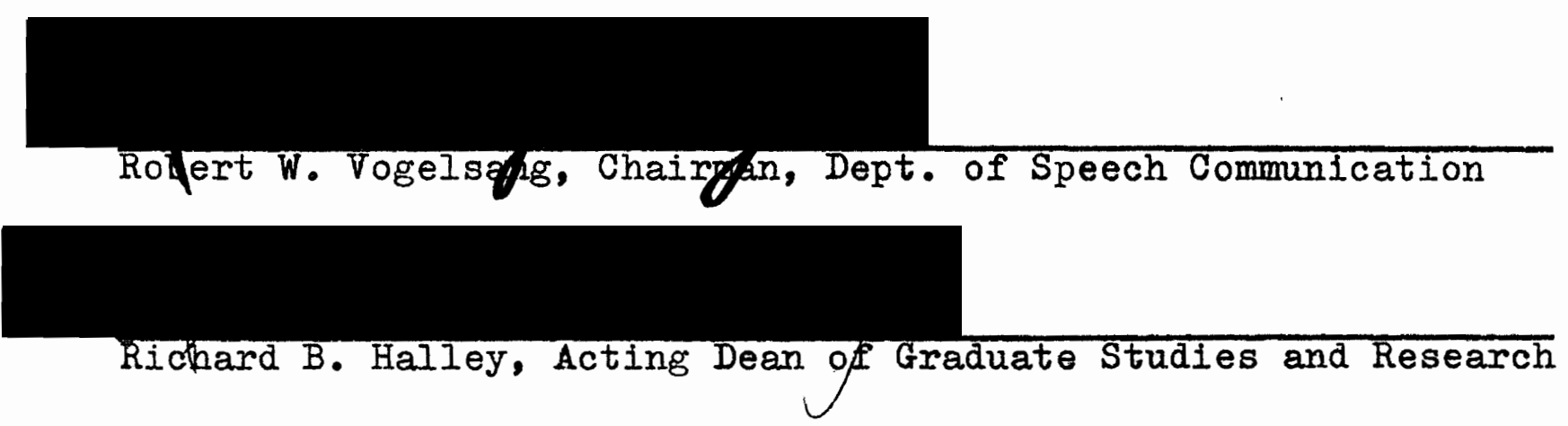




\section{ACKNOWLEDGNEINTS}

I wish to express thanks and appreciation to:

Dr. James Maurer, my academic advisor, for his generosity and assistance not only in time spent on this study, but also in the use of his office and equipment, without which my study would have been impossible.

Mrs. Mary Gordon and Dr. Steve Brannan for serving on my thesis committee.

Mr. Michael Fairchild for his expertise and assistance with the statistics necessary for this project.

Dr. Stephen Fausti for his confidence and support in all of my professional activities. 
TABLE OF CONTENTS

PAGE

ACKNOWLEDGMENTS

IIST OF TABIES

IIST OF FIGURES

CHAPTER

I INTRODUCTION AND STATEMENT OF PURPOSE . . . 1

Statement of Purpose. . . . . . . 2

II REVIEW OF THE LITERATURE. . • . • • • • 4

Incidence and Prevalence of Hearing Loss Among Older Persons . . . . . . 4

Anatomy and Acoustics of Hearing. . . 7

The Acoustic Reflex . . . . . . . 14

Borg's Research to Establish the Reflex Arc . . . . . . . . . . . 19

The Efferent System . . . . . . 24

Critical Band Concept . . . . . . 26

Presbycusis . . . . . . . . 33

Measurement of Acoustic Impedance . . 38

III METHOD. . . . . . . . . . . . 45

Instrumentation . . . . . . . 46

Test Procedure. . . . . . . . 50

Data Analysis . . . . . . . 53 
CHAPTER

PAGE

IV PRESENTATION OF RESULTS • • • • • • • • • 55

Discussion of Results and Implications. . 65

Clinical Implications . . . . . 65

Theoretical Implications. . . . . 67

V SUMMARY AND IMPIICATIONS. • • • • • • • 70

Implications for Further Research . . . 71

REFERENCES • • • • • • • • • • • • • • • • 73

APPENDIX A. • • • • • • • • • • • • • • • • • 81

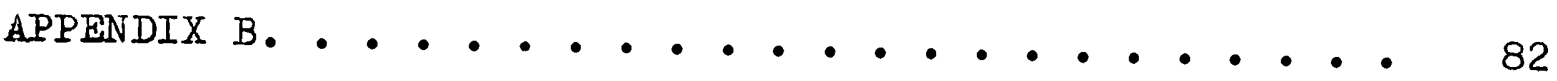




\section{IIST OF TABLES}

PABIE

PAGE

I Incidence of Hearing Loss . . . . . . 5-6

II Examples of Critical Bandwidth. . ..... 28

II Criteria for Assessment of Hearing Sensitivity. . . . . . . . . 53

IV Assessment of Severity of Loss. . . . . . 56

$V$ Distribution of Errors - Assessment of

Severity. . . . . . . . 56

VI Prediction of Slope of Loss . . . . . . 58

VII Distribution of Errors - Assessment of Slope. 59

VIII Assessment of Both Slope of Loss and Severity 60

$X$ Means, Standard Deviations, Ranges of Reflex

Thresholds. . . . . . . . . 61

XI $t$ Values--Normals and Geriatrics Reflex Threshold Levels. . . . . . . 64

XII Correlations Between Thresholds and Reflex

Levels. . . . . . . . . 65 
IIST OF FIGURES

FIGURE

PAGE

1 Schematic of Middle Ear Cavity, Frontal View.

2 The Ascending (Afferent) Neuronal Chain from the Cochlea to the Cortex .......

3 Schematic Outline of the Neuronal Organiza-

tion of the Acoustic Stapedius and Tensor

Tympani Reflexes. ..........

4 The Descending (Efferent) Neuron Chain. . .

5 Peripheral Auditory System and Block Diagram

of Air-Cavities and Middle-Ear Structures

That Contribute to Acoustic Impedance at

Plane of Measurement in External Auditory

Meatus. ............. 39

6 Diagram of Impedance Measurement Ear-Probe

and Related Measuring Devices . . . . 48

7 Distribution of Predictive Errors According

to Category of Prediction ...... . 57

8 Reflex Thresholds of Normal Young Adults,

Depicting Means, Ranges, and Standard

Deviations. . . . . . . . . .

9 Reflex Thresholds of Geriatric Adults,

Depicting Means, Ranges, and Standard

Deviations. . . . . . . . . . 
CHAPTER I

\section{INTRODUCTION AND STATEMENT OF PURPOST}

The invention of the impodance bridge and the perfection of tympanometry has opened an ontirely new field in audiological assessment of hearing sensitivity. Impedance audiometry has two clinical utilities: 1) to measure the compliance of the middle ear, and 2) to monitor the intraaural reflex. The reflex is monitored as a change in the physics of the middle ear, i.e., a change in impedance and admittance values. This usually happens in response to contralateral stimulation of 70 to $90 \mathrm{~dB}$ above hearing threshold level. Among the uses of monttoring the acoustic reflex has been its diagnostic value for disorders of the eighth nerve and lower brainstem as it is elicited bilaterally in normal subjects. In order for it to be elicited contralaterally, both afferent and efferent pathways of the VIII nerve must be intact as well as those of the VII nerve prior to the stapedial branch. The stapedial tendon must be intact and attached to the head of the stapes, and there must be sufficient mobility in the ossicular chain to allow contraction (Feldman, 1963). Since the contralateral reflex threshold of normal subjects occurs at levels of 70 to $90 \mathrm{~dB}$ above hearing threshold level, many cases may 
be studied which would not be possible with standard audiological procedures.

Recently, the acoustic reflex has been used as a means of assessing hearing loss and slope of loss in a wholly new approach to assessment of hearing sensitivity (Jerger, 1974). A basic assumption of this method is that different sounds have different degrees of perceived loudness, and, therefore, different threshold values. The relationship between different types of stimuli has been the basis for a new test of assessment of hearing sensitivity.

Review of the literature has shown that no research has been conducted using this method of hearing assesment on a purely geriatric sample of the population. Since additional variables such as conductive loss from stiffening of ligaments, muscles, and connective tissues, enlarged ear canals, and recruitment of loudness enter into the teating of the older person, a study of the reliability of this method should prove useful for clinical and research purposes.

\section{Statement of Purpose}

The purpose of this study was to determine if the method of assessing hearing loss and slope of loss is statistically valid when applied to a sample of the geriatric population with no known concommitant otologic problems other than presbycusis.

The principle questions posed in this study were: 
1) Will the determination of acoustic reflex thresholds be statistically valid in assessing magnitude of hearing loss in this sample of persons over sixty-five years of age?

2) Will acoustic reflex thresholds be statistically valid in assessing slope of loss among members of this sample?

3) Will reflex thresholds of tho older population group be statistically different from those of the young adult control group? 
CHAPTER II

REVIEW OF THE ITTERATURE

\section{Incidence and Prevelence of Hearing Loss Imong OIder Rersons}

According to data obtained by the National Health Survey which was conducted by the United States Department of Health, Education, and Welfare during the period from October, 1960 to December, 1962, the age group of sixty-five years and older is the segment of the population which is most severely afflicted with problems of hearing impaiment.

Data obtained from this suevey further showed that 28.2 percent of adults with hearing 108 s of +16 ar or greater (ASA 1951 standards) were in the age range from sixty-five to seventy-four and 48 percent were in the range from seventy-five to seventy-nine years; whereas, .8 percent were in the age range from eighteen to twenty-four years. These statistios clearly demonstrate the area of greatest hearing difficulty exists within the geriatric population and are more extensively illustrated in Table I. The United States Department of Health, Bducation, and Welfare projects (based on these statisties). that approximately twenty-four million persons over sixty-five years of age will suffex from impaired hearing by 1980. 


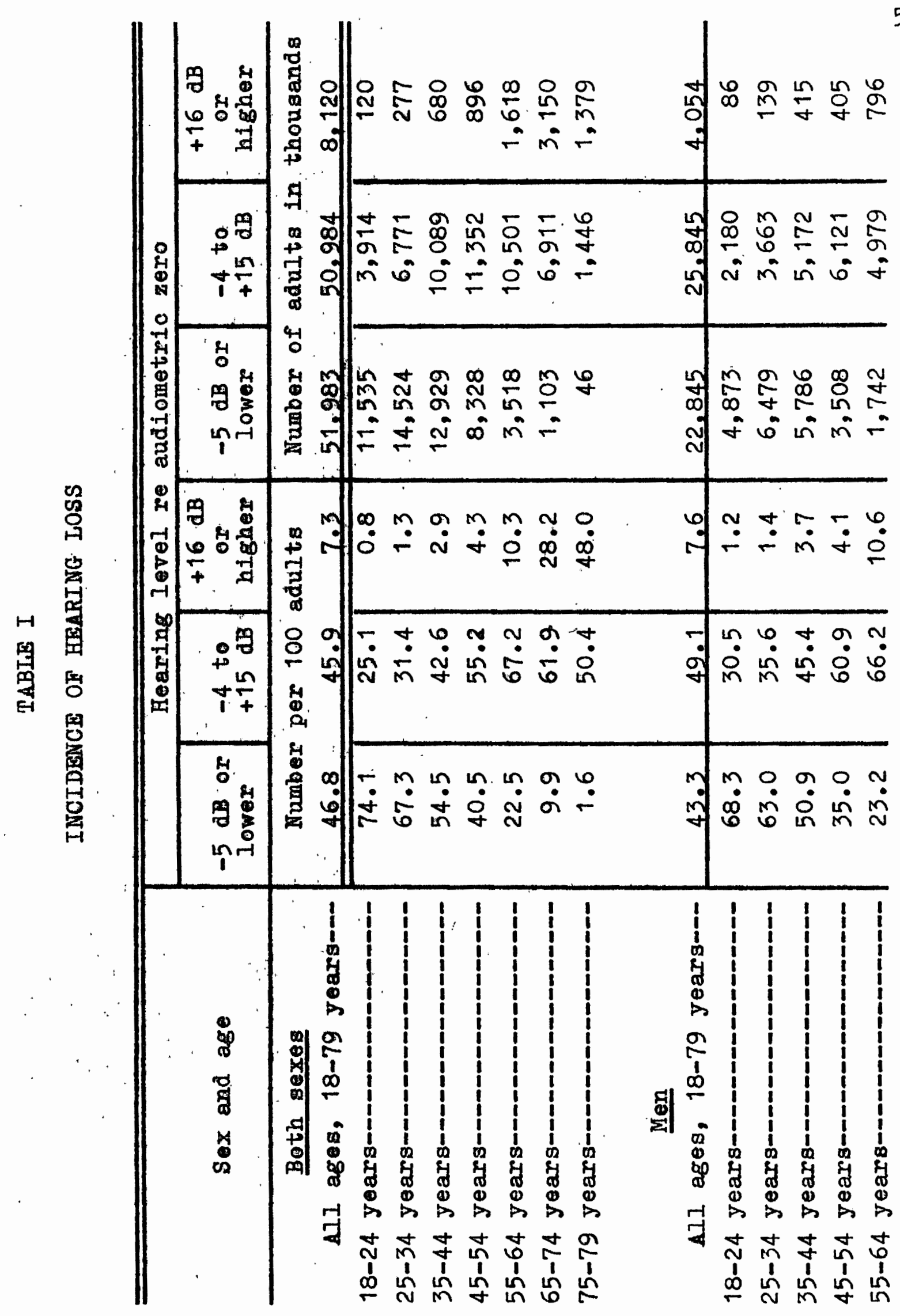




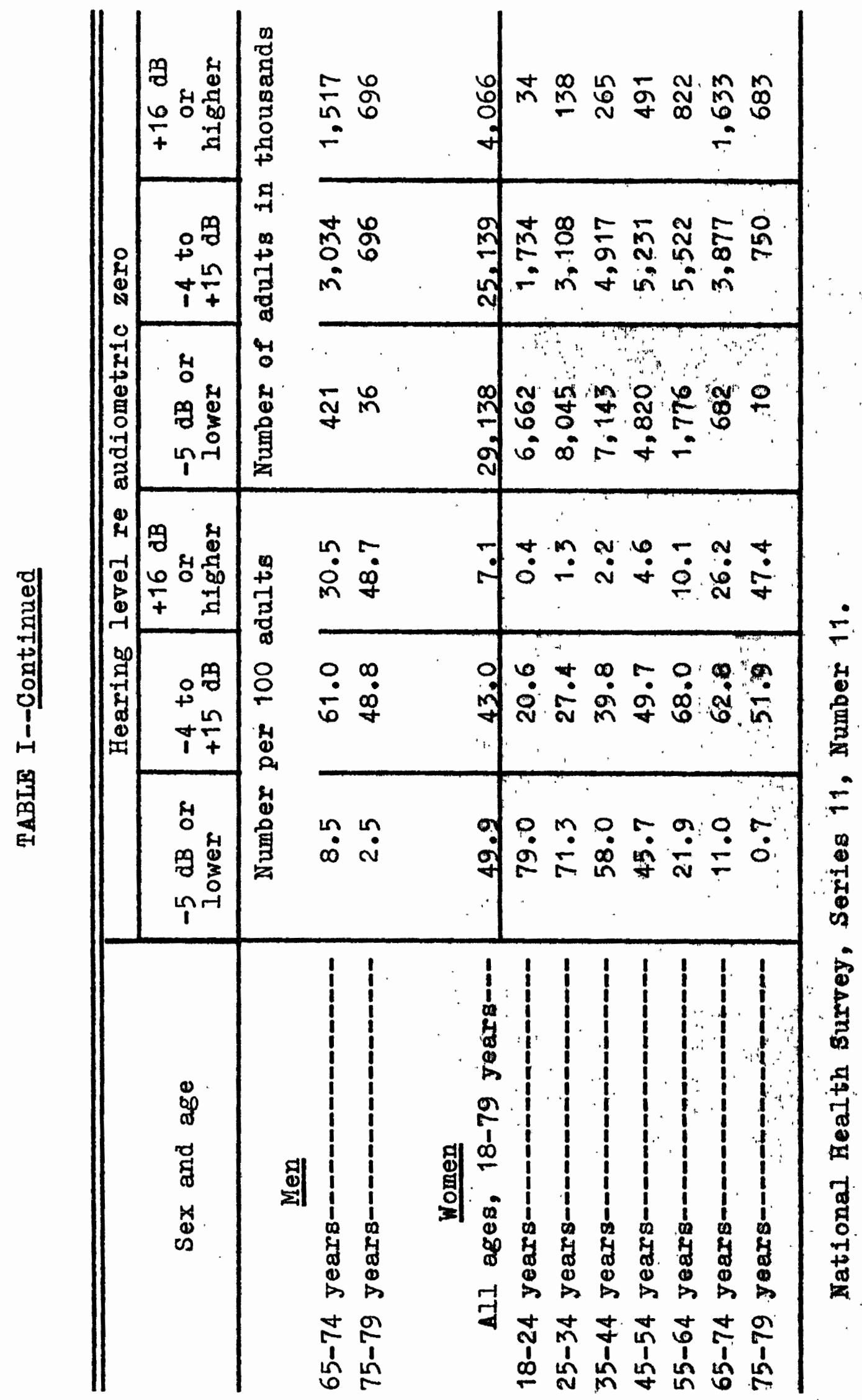


Rupp (1970) stated that almost nineteen million (10 percent of the total population of the United States) are sixty-five years of age or over. More than a milition are over elghty-five, and some six million are between the ages. of seventy-five and eighty-five. dccording to these senior citizen's own opinion poll, viston and hearing are ranked first in importance for a healthy old age. At the present time, this is not possible for a majority of older persons; 90 percent of those over sixty-five years of age need glasses and 66 percent have serious hearing problems by the age of eighty (Rupp, 1970).

\section{Acoustics and Anatomy of Hearing}

In order to understand the role of the middle ear reflexes in hearing, it is necessary to review certain aspects of the anatomy and functioning of the ear. The process begins as sound waves enter the pinna which serves as a funnel to direct sound waves through the external auditory meatus to the tympanic membrane. The extermal auditory meatus is a curved, irregularly-shaped tube which conducts sound waves to the tympanic membrane and serves as a frequency filtering device (Zemlin, 1968). Wever and Iawrence (1954) estimated the speed of sound in the meatus to be 350 meters per second. Fleming (1939) found the resonant frequency of the meatus to be $3800 \mathrm{~Hz}$. This has been confirmed by later investigation (Zemlin, 1968). 
Sound waves traveling in a medium of a definite elasticity and density will not pass easily into another medium of different elasticity and density; a portion will be reflected away. In any system which has efficient transmission of energy, the impedance of the receiving medium must match that of the transmitting system. In the ear, the impedance of the waves in air must somehow made to match that of the liquids of the inner ear. In order to do this, the middle ear must increase the pressure at the oval window by a factor of sixty-three, or by about $28 \mathrm{~dB}$. Wever and Lawrence (1954) found the ratio between the area of the tympanic membrane and stapes foot-plate to be $21: 1$. When combined with the ossicular lever ratio, this affords a mechanical advantage of 18:3, or an increase in SPL of about $25.5 \mathrm{~dB}$ (2emlin, 1968). As a result of resonance in the auditory canal, the sound pressure at the eardrum is higher than at the entrance of the canal with a $10 \mathrm{~dB}$ peak around $3500 \mathrm{~Hz}$. (Moller, 1972).

In 1561, Fallopius was the first person to describe the middle ear and give it the name "tympanum," or "army drum." The lateral wall of the middle ear is formed by the tympanic membrane, which is concave, smooth, and pearl gray. It consists of three layers of tissue: 1) a thin, outer, cutaneous layer; 2) a fibrous, middle layer; and 3) an internal layer of mucous membrane. A small portion of sound waves impinging upon the tympanic membrane is absorbed; 
a major portion is reflected back into the external auditory meatus. The reflected portion is measured in tympanometry (zemlin, 1968).

The middle ear, or tympanic cavity, is an irregular space within the petrous portion of the temporel bone. It consists of two parts: the tympanic carity proper, and the epitympanic recess, which extends above the level of the tympanic membrane (Zemlin, 1968). The largest part of the tympanic cavity is filled by the ossioles (the malleus, incus, and stapes), the three smalleat bones of the humen body; which transmit sound waves to the inner ear (see Figure 1). The head of the malleus and the bulk of the

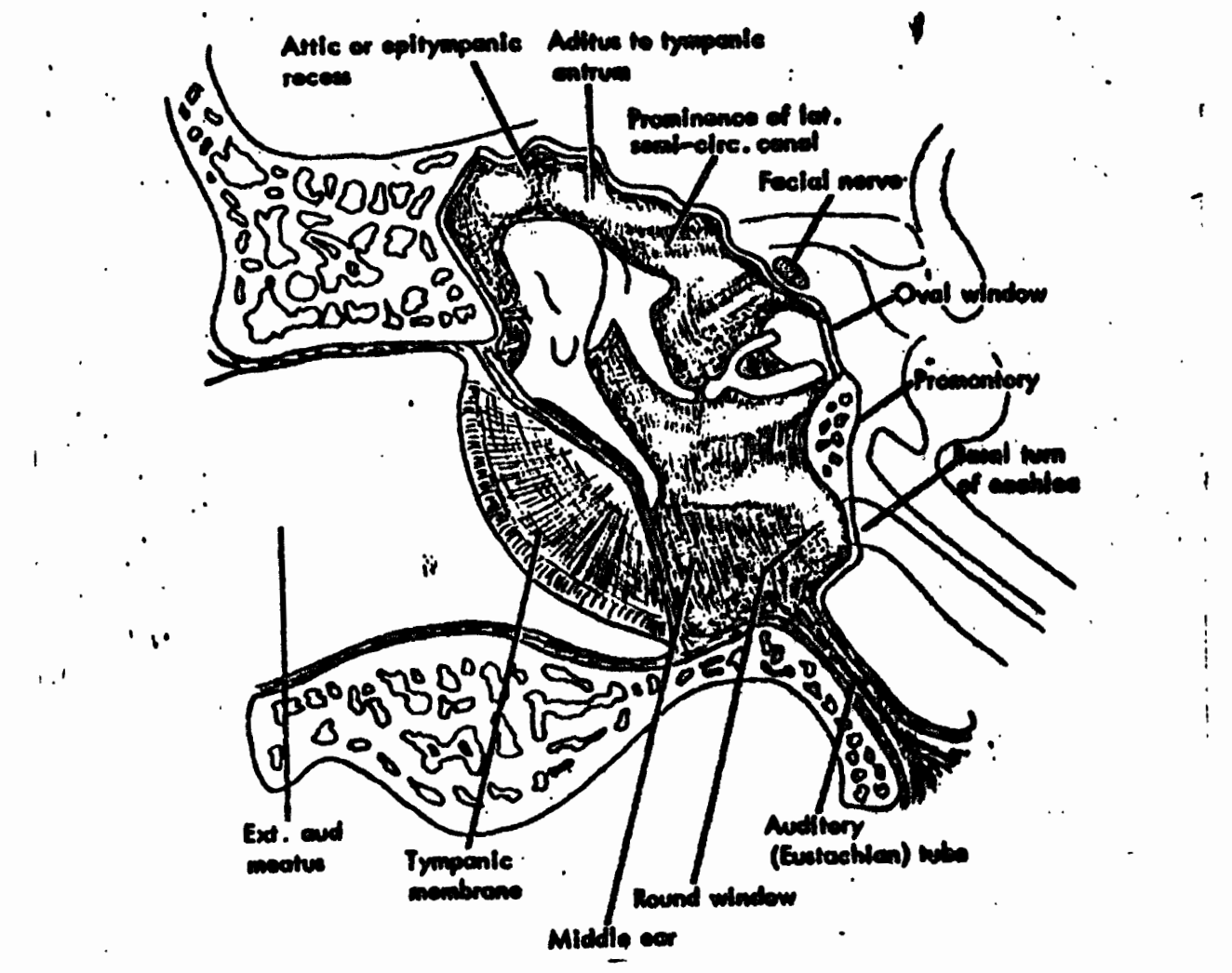

Eigure 1. Schematic of midale ear cavity, frontal view (Zemlin, 1968). 
incus extend up into the epitympanic recess. The footplate of the stapes fits into the oval window, where it is fixed into place by the annular ligament. The oval window and the round window are two openings in the bony medial wall of the middle ear cavity; the round window is closed by a thin membrane. As the pressure waves travel through the middle ear by way of vibrations of the ossicular chain, the footplate of the stapes is rocked back and forth, thus transmitting pressure waves to the liquid-filled cochlea of the inner ear.

The ossicles are suspended by a series of ligaments; the malleus is suspended by three ligaments, the incus by one. Due to the method of suspension, the inertia of the system is very small and its rotational axis is near the center of gravity. This causes abrupt damping of the sound transmission once vibrations have ceased (Zemlin, 1968). In addition to the IIgaments which suspend the ossicular chain, the malleus and stapes bones are attached by tendons to the two intra-ear muscles, the tensor tympani (25 mm. in length) and the stapedius ( $6 \mathrm{~mm}$. in length), which are the two smallest striated muscles in the body. The tendons of these two muscles differ from other tendons because of the large amount of elastic tissue. Jepsen (1963) felt this elastic property served to dampen vibrations of the ossicles and to cause less sudden onset of muscle traction. The tympanic muscles have two unique 
features: their short fibers are arranged to give great tension with very little linear displacement, and they are completely encased in bony canals with only their tendons entering the tympanic cavity. Bekesy (1936) felt this arrangement reduces vibration which may interfere with sound transmission and also reduces the mass of the ossicular chain. Contraction of the stapedius pulls the stapes downward and outward at right angles to the direction of movement of the ossicular chain. This greatly reduces its force upon the liquids of the cochlea (Jepsen, 1963). The tensor tympani muscle originates in a bony canal nearly parallel to the canal of the Eustachian tube. The distal part of the muscle lies on a bony shelf, the cochleoform process, which acts as a pulley over which the tendon of the tensor tympani lies before bending and attaching to the upper part of the manubrium of the malleus. Contraction of this muscle draws the malleus at almost right angles to the direction of rotation of the ossicular chain and increases tension of the tympanic membrane (Jepsen, 1963). Recent research has suggested this action may not be triggered by loud sounds, but rather, as a general startle reflex (Klockhoff and Anderson, 1960).

The innervation patterns of the two muscles reflect their origins. Since the stapedius is developed from the second branchial arch, it is supplied by the nerve to that arch, the facial nerve. The tensor tympani, which develops 
from the first branchial arch, is supplied by the third branch of the trigeminal nerve. The middle ear is innervated by three cranial nerves: the acoustic or VIII nerve, the facial or VII nerve, and the trigeminal or $V$ nerve. The facial nerve has both a motor root and a sensory root. The motor root originates in the lower part of the pons. The fibers emerge from the brain at the level of the superior olive, where they join the sensory branch which originated in the geniculate ganglion. The combined roots of the facial nerve join the acoustic nerve and enter the internal acoustic meatus. At the bottom of the meatus, it separates and enters the portion of the facial canal which lies between the vestibule and the cochlea. As the faclal canal reaches the medial wall of the middle ear, it changes directions and forms a "knee" which is known as the geniculate ganglion. Behind the oval window, the facial nerve canal becomes vertical. At this point, the pyramidal eminence, which is a bony protuberance containing the stapedial tendon, is attached to the facial canal. It also contains the stapedial branch of the facial nerve which supplies the stapedius muscle (Wolferman, 1970)

The trigeminal is the largest of the cranial nerves. Its mandibular branch contains both motor and sensory fibers. Its motor root branches off the interior maxillary nerve and sends small filaments to the otic ganglion and thus supplies the tensor tympani muscle with motor fibers (Zemlin, 1968; Jepsen, 1963). 
The auditory nerve consists of both an afferent and an efferent branch. The afferent portion has its origin in the hair cells of the cochlea. Radial fibers innervate the inner hair cells while both radial and spiral fibers innervate the outer cells. Rasmussen (1953) estimated about 30,000 auditory nerve fibers are present in man; Schucknect (1956) found about 51,000 in the cat. There are about 500 efferent nerve fibers which terminate on both inner and outer hair cells (Rasmussen, 1960). The auditory nervo fibers divide in a regular way to send branches to each dorsal and ventral cochlear nucleus, from where they ascend through a series of synapses to the auditory cortex (see Figure 2).

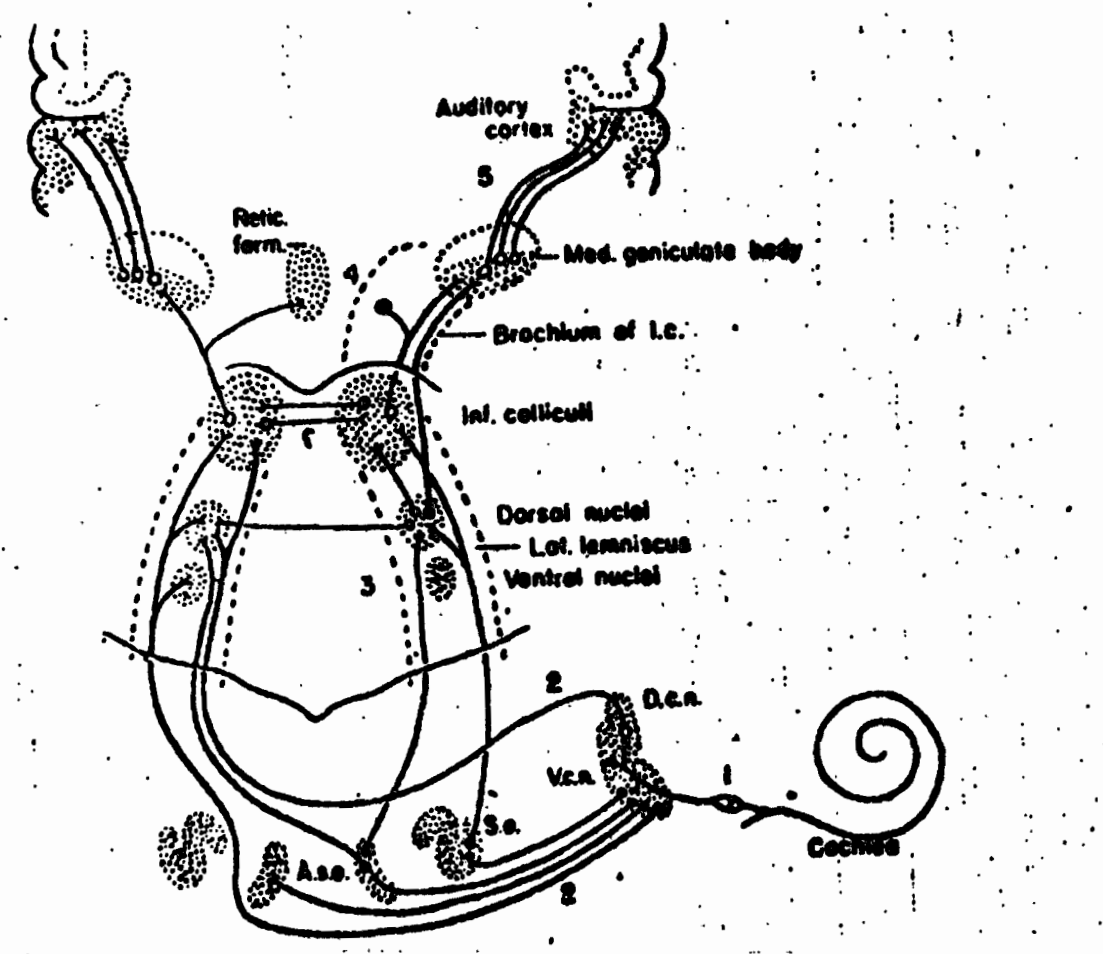

Figure 2. The ascending (afferent) neuronal chain from the cochlea to the cortex. Numbers indicate neuron levels (Gaecek, 1972). 


\section{The Acoustic Reflex}

In 1878, Hensen was the first to observe acoustic middle ear muscle reflexes of the tensor tympani in dogs. In 1913, Kato demonstrated acoustic reflex contractions not only emanate from the tensor tympani, but also from the stapedius. Iuscher's investigation later confirmed these observations. He was the first to show that acoustic reflex contractions of the stapedius were a constant phenomenon in man. He found that the upper and lower frequency limits for the elicitation of the stapedius reflex were $14,000 \mathrm{~Hz}$, and $90 \mathrm{~Hz}$, respectively, and demonstrated that the reflex threshold was lowest at $2000 \mathrm{~Hz}$. He also found that the reflex could be elicited both from ipsilateral and contralateral ears. Iindsay (1936) found the threshold of the stapedius reflex to be 65 to $85 \mathrm{~dB}$ above the threshold of normal hearing (Jepsen, 1963). Northern (1974) estimates that, in the normal ear, a loudness of from 70 to $100 \mathrm{~dB}$ will elicit an acoustic reflex, with the median being $82.2 \mathrm{~dB}$ (approximately $85 \mathrm{~dB}$ on the audiometer).

Band-pass filtered noise is a more effective stimulus in eliciting the reflex than pure tones. Moller (1962) found that if the energy content of a tone and a noise band centered around the same frequency are compared, noise can elicit the reflex at about $5 \mathrm{~dB}$ below the level of the tone. 
Jerger (1974) has found a $20 \mathrm{~dB}$ difference in the reflex thresholds of pure tones and broad band noise. Once threshold is passed, the strength of the muscle contraction increases roughly in proportion to the magnitude of the stimulus. It is active over a relatively narrow dynamic range between its threshold and level of saturation. The ability of the muscles to perform finely graded contractions is determined by the innervation ratio (ratio of efferent to motor fibers). The ratio in the tensor tympani is approximately 1:7; the ratio in the stapedius is from $1: 3.5$ to 1:5.6. These are unusually high ratios compared to other body muscles. The possibility of two kinds of motor units in middle ear muscles--tonic (characterized by continuous tension) and phasic (tension fluctuating) has been hypothesized by Okamato et al. (1954).

On the basis of animal studies (Wersall, 1958; Kirikae, 1960; Wever and Vermon, 1956; Galambos and Rupert, 1959), it has become fairly well established that contraction of the tympanic muscles results in a reduction in sensitivity to low frequency tones. Wever and Bray (1942) investigated the function of the stapedius muscle by observing the effects upon the electrical responses to the cochlea. They found that tension applied through a thread attached to the stapedius tendon causes a marked reduction in transmission for low tones, a smaller reduction for high tones, and improvement followed by decline for tones of the middle 
range. Borg (1968) found that attenuation of the acoustic reflex was greater at frequencies below the resonant frequency of the middle ear than above 1t. A tone of $500 \mathrm{~Hz}$. was attenuated from 12 to $15 \mathrm{~dB}$; whereas, a tone of $1450 \mathrm{~Hz}$. was attenuated only from 0 to $6 \mathrm{~dB}$.

There have been many theories advanced as to the primary function of the acoustic reflex. Among these are the accommodation to optimum sounds and the fixation theory, which proposes that the reflex provides needed rigidity for the ossicular chain and prevents changes in articulation between ossicles during high acceleration. Simmons (1964) warned that caution should be exercised in assigning a purely protective role to the acoustic reflex. He demonstrated that muscle reflexes can become active at much lower levels than assumed by the protection theory. As part of an animal's common orienting response to unusual environmental sound, the middle ear contractions take place along with obvious head and body movements. They serve to attenuate inborne sounds and help "tune" in on external stimuli. The reflex can take place with head movements, vocalization, chewing, and swallowing. Fletcher and Riopelle (1960) demonstrated the protective effect of the acoustic reflex in an experiment in which they triggered the reflex by a $1000 \mathrm{~Hz}$. tone at $98 \mathrm{~dB}$ SPI before exposing subjects to gunfire. of great practical interest is the latency period before onset of the acoustio reflex. When a tone is turned 
on rapidly, there is a characteristic delay interval between onset of the stimulus and onset of response.' Perlman and Case (1939) recorded this in human beinge at about ten milliseconds. Wever and Lawrence (1954) cited the'mean value of .06 seconds for the stapedius and .15 second for the tensor tympani. The magnitude of the latent poxiod is found to be inversely proportional to the strength of the acoustic stimulus. A range of from 40 to 160 milliseconds has been observed in human subjects when stimulated with a wideband noise of various intensities. The existence of the latent period has important practlcal and theoretical consequences in relation to the functioning and effectiveness of the acoustic reflex. Due to the latency, the reflex is unable to perform its postulated protective role when elicited by a very brief stimulus.

Bekesy (1936). showed another defense mechanism of the midale ear whereby the latency period is eliminated. At moderate sound pressures, the stapes rotates around a vertical axis, but when the sound pressure is greatly increased, the vibration axis is changed, so that the stapes rotates around a longitudinal axis through its base. The first movement causes an in and out displacement of cochlear fluid; the second causes the fluid to surge back and forth without any effect on the cochlea (Zemlin, 1968). Most information pertaining to the quantitive features of reflex dynamics were gathered by recording the input 
impedance to the ear. Assymetry is the most conspicuous feature of the on-off response. At every stimulus level, the on response is considerably faster than the off response (Dallos, 1964). This implies that the muscle contraction process is much more rapid than the relaxation. Dallos (1964) concludes the response dynamica depend pon both stimulus intensity and frequenoy. At any given frequenoy, there is apparently a given leedback gain that determines the basic nature of the response.

Moller (1962) found that reflex thresholds are approximately 5 to $10 \mathrm{~dB}$ higher with contralateral, as opposed to ipsilateral, stimulation. At any intensity above reflex threshold, the impedance change is less in the contralateral ear ( $\mathrm{Dallos}, 1973$ ).

Recent studies have led researchers to conclude the stapedius plays a more dominant role than the tensor tympani in altering transmission through the middle ear. Despite its smaller size and strength, it may be the more important of the two muscles in this respect. Contraction of the tensor tympani is believed to be associated with a general startle reflex rather than a reaction to loud sounds (Jepsen, 1963). Djupesland (1962) observed contraction of both tympanic muscles upon contraction of the perorbital muscles (eye muscles), and Klockhoff (1960) observed this after air-jet stimulation. The relations to frequency are somewhat different for the two muscles. 
The tensor tympani reduces transmission and shifts the sensitivity curve upward along the frequency scale. For the stapedius muscle, there is no poticeable shift of the region of maximal sensitivity, which under tension remains about $3000 \mathrm{~Hz}$. There is, however, a significantly gxeater impairment of tones below this region than of tones above it; within the region itself, there is alight attunement (DaIlos, 1973).

\section{Borg's Research to Establish the Reflox Arc}

Several investigators have studied the reflex arc of the tympanic muscles. Among these are Hammerschlag, 1899; Forbes and Sherxington, 1914; Lorente de No, 1933; Tsukamoto, 1934; and Rasmussen, 1946; but previous to Borg's (1973) colossal research project on the neuronal organization of the acoustic midale ear reflex, the pathways of this reflex had not been studied in detail. The acoustie reflexes and the olivo-cochlear efferent tract both influence the response of the cochlea to sound, but there seems to be important differences between these two systems at rarious frequencies and intensities. Because of the work of Rasmussen, the path of the olivo-cochlear bundle has besome well known, but the path of the acoustic reflexes has remained vague. The acoustic reflex appears to be the most regular, stable, and least complexly organized motor or anatomical response to sound. Since the acougtic stapedial reflex has become a 
widely used tool for diagnosis of hearing impairment, it becomes very important to understand the physiology and anatomy of the central routes of reflex activation. Prior to Borg's investigation, information was incomplete regarding the parts of the ascending pathway which were involved in middle ear reflexes.

Borg employed a combination of physiological and anatomical methods on rabbits with chronic brain lesions. His studies were based on retrograde reactions to neuron lesions of the pathways. From these studies, he came to the following conclusions regarding the neuronal organization of the middle ear reflex pathways:

The first synapse of both the stapedius and tensor tympani reflex pathways is in the ventral cochlear nucleus. The dorsal cochlear nucleus is not involved, at least with pure tone stimulation. It is believed that the thin fibers of the ventral cochlear nucleus are the ones involved in motor responses since they are, the same size as the thin fibers of the trapezoid body and have bilateral connections to the medial superior olive body.

Borg did not conclusively prove the location of the second synapse of the stapedius reflex, but he believed that all evidence points to the medial superior olive as having both crossed and uncrossed connections to the ventral cochlear nuclei and to the ipsilateral seventh nerve. Rasmussen (1964) noted this earlier when he observed crossed 
connections from the medial superior olive to the contralateral seventh nerve in the cat. The pathway of the crossed stapedial reflex has a synapse either in the ipsilateral or contralateral medial superior olive. Results of the study indicated uncrossed and crossed connections from the medial superior olive and a direct path from the ventral cochlear nucleus to the contralateral seventh nerve.

The tensor tympani reflex first-order and second-order neurons follow the same course as for the stapedius reflex to the level of the trapezoid body. It is thought to proceed to the medial superior and possibly to the ventral nucleus of the lateral lemniscus.

The third synapse of the reflex are is the connection with motor neurons; this is the VII or facial nerve for the stapedius and the $V$ or trigeminal for the tensor tympani. The majority of studies indicate that motor neurons for the stapedius are situated in the medial group of the VII nerve together with the motoneurons of the external ear muscles. The location of the neurons which connect the tensor tympani with the trigeminal nerve are not well understood. At the present, no direct connections from second-order neurons to the cranial nerve $V$ have been established (Borg, 1973). The motor neurons follow the facial nerve to the stapedius in the middle ear and the mandibular branch of the trigeminal nerve to the tensor tympani. There are also indirect pathways which lie parallel 
to the direct paths; these indirect pathways are slower. Researchers have speculated on the involvement of the extrapyramidal system in the slow activity since Massion (1949) found that the cells of the red nucleus of the cat and rabbit respond to sound. Lorente de No (1933) pointed out that connections to the motor nuclei from the nuclei of the lateral lemniscus, which descend from the inferior colliculus, suggest alternative pathways. Further evidence implies the motor nuclei of the middle ear muscles are exposed to reflex activity from the brain-stem reticular formation and from certain sensory areas of the skin and face (Moller, 1962).

The work of Borg (1973) thus revealed the presence of two ipsilateral and two contralateral direct pathways of the stapedial acoustic reflex. It also revealed one ipsilateral and one contralateral path for the tensor tympani reflex. Borg's work suggests the two peripheral control systems, the midale ear reflexes and the olivo-cochlear efferent bundle, seem to be organized in two separate neuroanatomic systems. The two systems are not completely independent, however, as the complete interruption of the crossed ollvo-cochlear bundle lowers the threshold of the midale ear reflexes for sound above $2000 \mathrm{~Hz}$. Borg concluded that this influence is probably at the cochlear level. Figure 3 illustrates the paths of the ipsilateral and contralateral acoustic reflexes. 


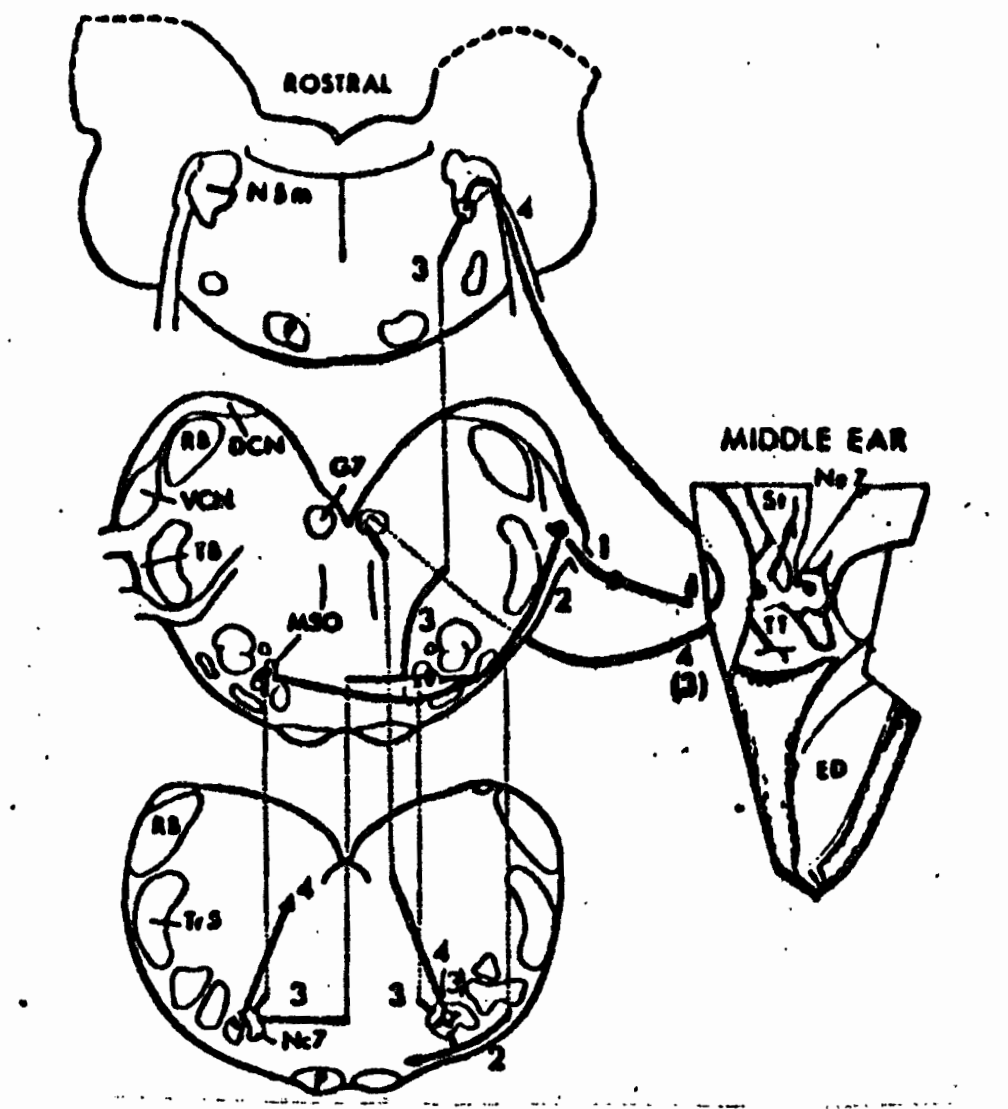

Figure 3. Schematic outline of the neuronal organization of the acoustic stapedius and tensor tympani reflexes shown in 3 transverse sections through the rabbit brain stem. The middle ear is shown schematically in posterior view. Solld lines represent nerve tracts. Dotted Ines show the connections between the sections. The stapedius reflex: The first neuron (1) the primary acoustic neuron from the hair cells to the cochlear nucleus has contact with the second-order neuron (2) in the ventral cochlear nucleus. The second neuron (2) passes in the trapezoid body and has contaot directiy with the ipsilateral stapedius motoneurons in the facial. motor nucleus (4(3)). Via interneurons (3) in, or near, the medial superior olive, it relays to the ipsilateral and contralateral facial motor nucleus. The motoneuron ( 3 or 4 ) follows the facial nerve to the stapedius in the middle ear. The tensor tympani reflox: The firstorder (1) and the second-order (2) neurons follow the same course as for the stapedius reflex. There are no direct connections from second-order neuron to the trigeminal motor nucleus. The motoneuron (4) follows the mandibular branch of the trigeminal nerve to the tensor tympani in the middle ear (Borg, 1973). 


\section{The Efferent Syatem}

Due largely to the work of Rasmussen (1946, 1953, 1960, 1967) the presence of a system of descending, centrifugal fibers, linking the cortex with the organ of Cort1, has been conclusively demonstrated. Two descending chains of neurons, both arising in the auditory cortical areas, and both traveling the same pathways as the ascending aystem, have been determined (see Figure 4).

The olivo-coohlear neurons are the finel link in the descending chain. The entire bundle contains about 500 fibers--both ipsilateral and contralateral. It travels in

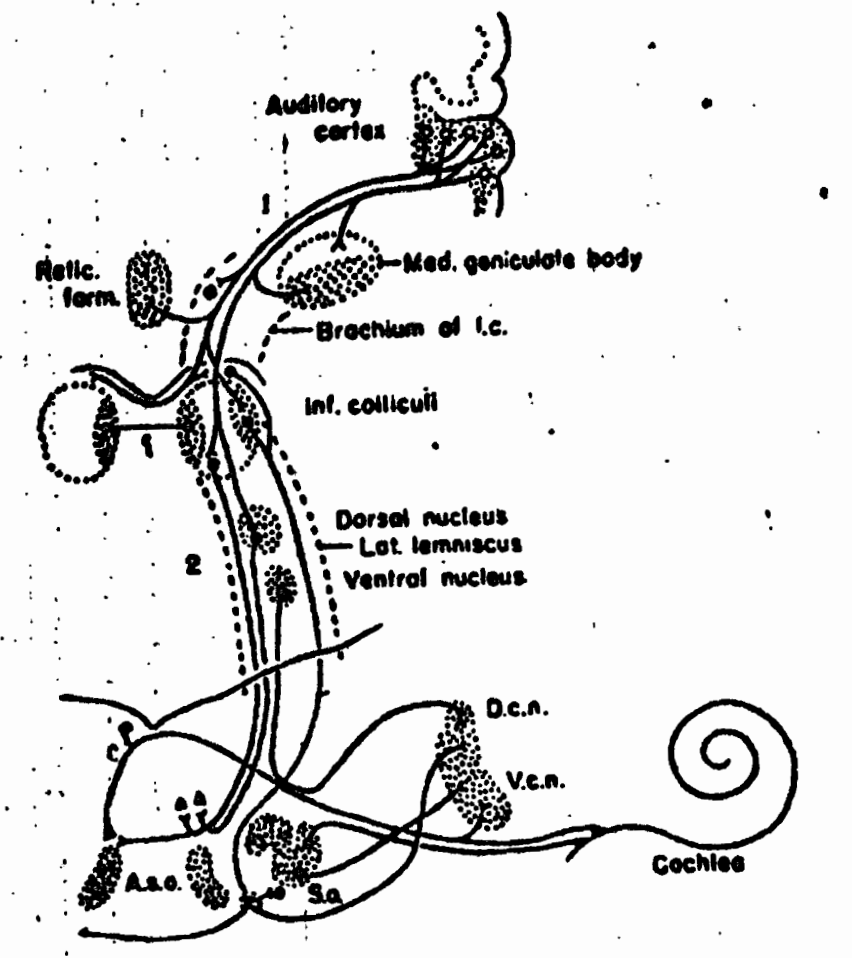

Figure 4. The aescending (efferent) neuron chains. Nerve fibers terminating in cochlea are those of the olivo-cochlear bundle (Gaecek, 1972). 
the vestibular branch of the VIII nerve and emerges from the brainstem between two divisions of the nerve. The cochlear efferents leave the vestibular nerve via the vestibucochlear anastomisis (Oort) and enter the cochlea in the basal region to form the intraganglionic spiral bundle within Rosenthal's canal. This bundle runs apicalward with fibers feeding off regularly. About 3000 efferent fibers enter the organ of Corti as a result of arborization. They course longitudinally under inner hair cells in the inner spiral bundle. About 800 fibers cross the tunnel of Corti and terminate in approximately 40,000 contacts with cell bodies of the outer hair cells (Dallos, 1973).

It is not fully understood how inhibition functions. The first physiological study of crossed centrifical fibers was made by Galambos, who used macroelectrodes to show that electrical stimulation suppresses the action potential at the round window of the cochlea. Another possible hypothesis is that efferent stimulation may cause changes in impedance in the organ of Corti. A working hypothesis presented is that the large efferent synapses cause post-synaptic hyperpolarization of the base of the external hair cells, which, in turn, counteracts the mechanism which releases transmitter substances for interaction of afferent impulses (Kimura and Wersall, 1955).

The ratio of efferent to afferent fibers is about 1:100. The efferents may have a means of detecting small 
changes in frequency and thus take part in some sort of frequency discrimination. It is estimated that the maximum inhibitory action of crossed efferent fibers in the ear corresponds to about 5 to $15 \mathrm{~dB}$. Fex (1967) concluded the centrifugal cochlear systems form part of a complex feedback mechanlsm, but there is no secure knowledge of how central connections are activated (Dallos, 1973).

The two inhibitory systems appear to operate in completely different ways. The acoustic reflex might be compared to a digital computer (it has an all or none reaction), while the efferent system resembles more closely an analog computer (it is effective on a continuum of sound intensity). The acoustic reflexes represent a lower brain-stem function, while the efferent system represents neural action from the level of the auditory cortex down the entire pathway. The acoustic reflex lowers sound transmission by altering the physical properties of the middle ear; the efferent system appears to lower sound transmission by altering transmission qualities of the neural components of the inner ear.

\section{Critical Band Concept}

Studies of human observers to bands of noise and other complex sounds have led to a measure of what appears to be a basic unit of hearing, the critical band. The concept of the critical band is a very important factor in measuring reflex threshold. Jerger (1974) has defined the critical 
band as a certain width on the basilar membrane that is essentially independent in terms of its loudness contribution from its neighbors. Jerger (1974) employed the concept of the critical band to explain the difference in reflex thresholds elicited by white noise and by pure tones. He found the basis for this phenomenon seems to be that the acoustic reflex (the stapedius contraction) is based upon the apparent loudness of a sound rather than on its actual physical intensity. Decibel for decibel, a broad band noise contains energy in many contiguous critical bands.

In the human cochlea, the estimated critical band at $1000 \mathrm{~Hz}$. covers from one to two millimeters of the basilar membrane. The fact that this loudness function bears a close resemblance to several functions of frequency such as difference limen for frequency and the mel scale for pitch (Bekesy and Rosenblith, 1951) makes it appear that all functions of loudness and frequency correspond to constant distances on the basilar membrane. The critical band concept corresponds to constant distances on the basilar membrane. If there are assumed to be 24 critical bands on a 32 millimeter long membrane, each critical band represents about 1.3 millimeters of topography on the basilar membrane. The following table (Table II) by Scharf (1970) demonstrates the number and width of the critical bands as well as the upper and lower cutoff frequencies. It is apparent the width of the critical bands increases with each increase in frequency 


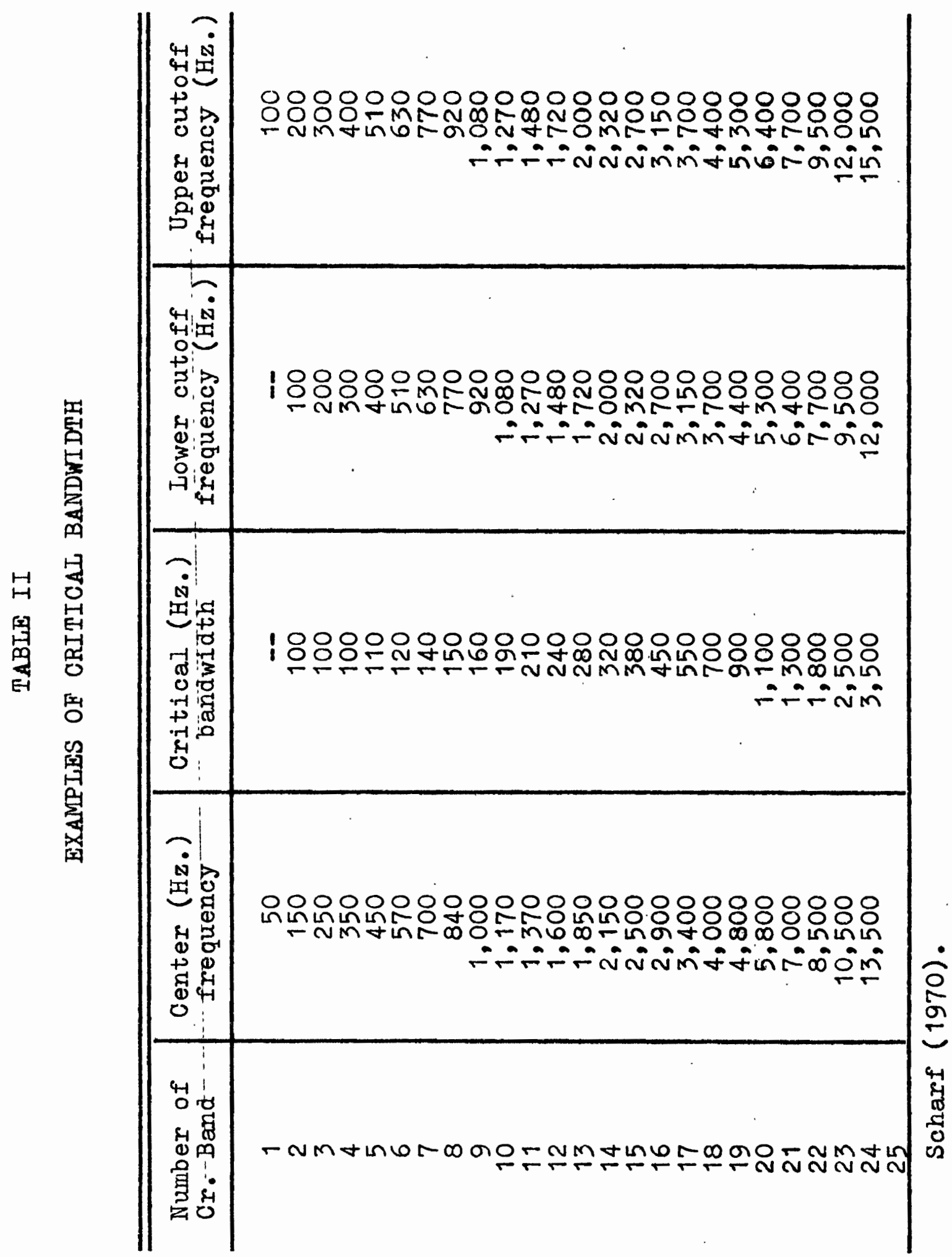


and the area above $1000 \mathrm{~Hz}$. contains many more critical bands than the area below it.

Fletcher (1940) hypothesized the existence of a critical band for masking. He suggested that when a white noise masks a tone, only a relatively narrow band of frequencies surrounding the tone does the masking. Energy outside this area contributes relatively little or nothing.

Gassler (1954) made careful measurements of the phenomenon of the threshold of complex sounds. His results indicated that total energy necessary for a sound to be heard remains constant as long as the energy is contained within a limiting bandwidth.

Zwicker (1958) advanced the theory that the loudness of a pure tone is a composite loudness because the displacement of the basilar membrane is spread over many critical bands. He assumed the "Ioudness" of these critical bands summates to give total loudness to a tone. Following this assumption, the loudness of a noise is thought to equal the sum of the individual loudnesses of the component critical bands.

Many researchers have studied the critical band mechanism in persons with sensori-neural hearing losses. Among the first investigators were Iightfoot, Carhart, and Gaeth (1953). They plotted masked threshold shifts against masker level over a wide range of effective masking. They found that persons with sensori-neural loss showed less masked threshold shifts at low frequencies and more at high fre- 
quencies than normal hearing persons.

De Boer (1960, 1964) was the first to report direct measures of the critical band in a pathological ear. He found strong evidence of an enlarged critical band. Jerger, Tillman, and Peterson (1960) used masking by octave bands of noise in tests with patients with impaired hearing and discovered that the hypacusic ear has a greater spread of masking rather than an altered signal to noise ratio. This difference was noted for remote (downward) and upward masking, but not at frequencies within the masker band. At an effective masking level of $30 \mathrm{~dB}$, hypacusic patients exhibited 5 to $15 \mathrm{~dB}$ more remote and upward masking (especially upward) than either normal hearing persons or those with conductive losses. Ritmanic (1962) found that sensori-neural patients and normal hearing persons exhibited the same masking effect at the center frequencies of the masking bands, but the sensori-neural subjects exhibited from 10 to $20 \mathrm{~dB}$ more remote and upward masking at all frequencies from 250 to $4000 \mathrm{~Hz}$.

Scharf and Hellman (1966) found that in ears with cochlear impairments and an average hearing loss of $65 \mathrm{~dB}$, the critical band was much wider than normal, because loudness did not change with changes in frequency. This was true with an increase of six or seven normal-sized critical bands.

Among the most recent researchers is Martin (1974), who 
used a loudness balancing technique to compare the relative loudness of a pair of tones as compared with a $2000 \mathrm{~Hz}$. single tone on both normal hearing subjects and those with sensori-neural hearing loss. The subjects with sensorineural hearing loss showed a reduced loudness effect which might suggest a widening of the critical band mechanism. Jerger (1974) feels that the abnormal widening of the critical bands, coupled with the loss in high frequency sensitivity so characteristic of sensori-neural hearing loss would have a substantially greater effect on the total loudness of a broad band noise than on the loudness of individual sinusoids within that band. Jerger (1974) defines loudness as that neural activity which bears a one-to-one correspondence with a human Iistener's loudness experience. "We assume that the reflex mechanism operates on that parameter of neural activity to which human listenęs typically assign the psyohological gonstruct 'lougness'! (Jerger, 1974). The result would be a reduction in the loudness advantage enjoyed by broad band noise in the normal ear.

The critical band mechanism may be compared to a set of band-pass filters with a variable center frequency, which seems to discriminate between sound energy within the band and that outside it. Several experiments have led to the theory that the locus of the critical band mechanism is perhaps in the cochlea (Niese, 1960; Bekesy, 1960). The largest support for the theory of the locus of the critical 
band mechanism being peripheral came from Bekesy's experiments (1960) of inhibition in the eye and on the skin of units of sensation and inhibition. Bekesy named these "neural inhibitory units." Zwislocki (1965) suggested these neural units may correspond to the critical band in the ear with each critical band corresponding to about 1300 neurons. He related these neural units to lateral inhibition in the receptor organ; in the ear, this meant the neural network of the cochlea. Scharf (1970) felt that all data leads to the conclusion that the critical band may be just one stage of a multi-stage filtering process which includes mechanical filtering on the basilar membrane, neural filtering in the cochlea, and additional neural filtering at higher stages in the auditory system.

The procedure employed in this new method of testing (SPAR Test) consists of eliciting the acoustic reflex by pure tones and by broad band white noise. A pure tone causes loudness sensation only within its critical band; a series of critical bands sums the contributions to form a total loudness. Since broad band noise excites all critical bands, less intensity is required to elicit a reflex by its use in normal ears than is required by use of a pure tone stimulus. In the case of sensori-neural hearing loss, the critical bands are believed to have widened, and, consequently, decreased in numbers. More energy is required to elicit a reflex by broad band noise than in normal ears. The rela- 
tionship between the two thresholds is the basis for prediction of hearing sensitivity.

\section{Presbycusis}

Hearing loss that develops as a function of advancing age has been termed presbycusis. In spite of the fact that it represents the most common cause of loss of hearing sensitivity among sensori-neural disorders in adults, it has been long neglected. Formerly, the popular theory was that presbycusis was due to atrophy of the organ of Corti and the spiral ganglion cells. More recent evidence (Hinchcliffe, 1962a) has suggested it also includes changes in the external and middle ear mechanisms:as well as deterioration of tissues in the central auditory pathways and auditory cortex. Glorig and Davis (1961) have reported data which suggest a conductive component in presbycusis. Their results revealed an air-bone gap that increased progressively with higher frequencies and advancing age. This report served as primary motivation for an investigation by Sataloff, Vassalo, and Menduke (1965); their research failed to find any evidence of an air-bone gap in presbycusis. Goodhill (1969) feels presbycusis should not be restricted to sensori-neural disorders, as the aging process occurs in ligaments, muscles, and connective tissue. Mechanical lesions occur in the middle ear involving the tympanic membrane: and the ossicular chain. Among these, it is quite likely that primary 
malleal fixation is a significant type.

Schuknecht (1964) has identified four types of presbycusis: sensory, neural, metabolic, and mechanical. Sensoxy or epithelial involves atrophy of the organ of Corti and the auditory nerve at the base of the cochlea. The primary site of degeneration in the cochlea is probably the supporting cells. Neural presbycusis is the result of loss of neurons in the auditory pathways and cochlea. This is the cause of a condition known as phonemic regression described by Gaeth (1948). This is a condition often encountered in the older person in which speech discrimination difficulties are greater than might be expected from the pure tone thresholds exists.

Metabolic presbycusis is thought to be caused by defects in the physical and chemical production of energy used by the sense organs. It is believed to be due to atrophy of the stria vascularis which is responsible for maintenance of bioelectric and biochemical properties of the endolymph. Alterations of these properties affect the entire scala media, resulting in a flat audiogram.

Mechanical presbycusis is believed to be due to a disorder of the mechanics of the cochlear duct which could result in loss of elasticity of the basilar membrane. The resulting audiogram shows the greatest loss in the high frequencies.

Welford and Birren (1965) discussed the aging process 
in the neural system which causes a difference in the rate of conduction of nerve fibers; this, in turn, causes the neural message to be spread out in time as it reaches cortical centers and produces a "blurring." They attribute poor discrimination to increased "neural noise" and a lowered resistance to noise interference which they believe to be caused by loss of central cells and random neural activity. They also believe that a "blurring" effect may be due to longer aftereffects of neural activity which could cause distortion in a fast, continuously varying stimulus such as speech.

Gerard (1967) relates deficits in the aged with a decreased number of functionally available neurons and a prolonged time of fixation of an experience or memory. He says that neurons may become unavailable either by anatomical loss or by irreversible entry into a fixed neuron assembly, He feels that summation of neurons at synapses and ease of irradiation of activity through neuron nets diminishes with age.

Konnigsmark (1969) classified cell changes due to aging into six categories and arrived at the conclusion that each classification of cells has its own life span and that the aging process appears to vary from cell to cell and organ to organ. He felt all of these processes are likely to be found in the auditory system.

A number of recent investigations have revealed 
histological evidence of aging in the auditory system. Kirikae (1964) discovered considerable evidence that signs of degeneration due to age have been identified in the central auditory nervous system. Changes in the major nuclei of the auditory pathways and auditory cortex were noted. Among these changes were a decrease in number of cells, atrophy and shrinkage of cells, accumulation of pigment, and a ghostlike, indistinct appearance of cells.

Makishama (1967) found that arteriosclerotic narrowing of the internal auditory axtery correlated positively with atrophy of the spiral ganglion and with degree of impairment. Johnson and Hawkins (1972) found that aging is characterized by a disappearance of capillaries in the auditory system. Krmpotic-Nemanic (1969) has found increased deposits of bone in the internal auditory meatus in the region of the spiral tract in the area corresponding to the basal turn of the cochlea. She feels the increasing pressure from these bone deposits may lead to tinnitus, to over sensitivity to loud sounds, and to eventual degeneration of spiral ganglion cells. Krmpotic-Nemanic stated:

In aging, a progressive apposition of dense connective tissue, osteoid, and bone, respectively occurs in the bottom of the internal auditory meatus. It can be seen microscopically as closure and disappearance of the holes for the nerve bundles in the region of the basal coil and progresses towards the modiolar region. This new-formed tissue compresses the nerve fibers and possibly also the arteries passing through the spiral tract. The result is atrophy first of the corresponding nerve fibers on the periphery of the nerve bundles and later also of the ganglionic cells. It is possible that the compression of the arteries causes, in some cases, atrophy of the stria vascularis. 
Miany methods have been used and studies conducted to explain the aging process. As a result of these studies, the following factors have emerged as being contributors: 1) reduction in cell production, 2) extracellular deposition of materials, 3) aging of elastic tissue, cartilage, and bone, 4) overgrowth of cells, 5) accumulation of substances in neurons, muscle cells, liver cells, and the adrenal cortex, 6) intracellular changes of uncertain nature. It is likely that all of these types of processes occur in the auditory system (Naunton, 1973).

According to the hydrodynamic theory of Bekesy, each sound which stimulates the cochlea also stimulates the area below the maximal amplitude of vibration. In the light of this concept, presbycusis is seen as a type of degenerative disease whose effects start early in noise-laden civilized environments (Rosen et al., 1964). Glorig and Nixon (1962) conducted an investigation of persons who had lived and worked in a quiet environment and had never suffered acoustic trauma. Their finding confirmed the fact that presbycusis and noise-induced hearing loss are two separate entities. All of these investigations highlight the fact that biological aging and chronological aging (which is the basis for hearing surveys) are two separate processes which do not necessarily run in parallel courses.

There is a growing need for better understanding of presbycusis and other geriatric symptoms. The processes of 
social disengagement or dependence can be reduced by maximizing the geriatric patient's auditory abilities. Consonant with this goal, new methodologies in measuring the consequences of age on audition should be evolved. Investigations have been conducted using the method of comparing thresholds of acoustic reflex to predict hearing loss on populations ranging in age from 3 to 92 years of age (Jerger, 1974). No study has yet concentrated upon the effectiveness of this testing method on an exclusively geriatric population. Many members of the geriatric population prove to be very difficult to test by conventional audiological methods. An objective method of predicting hearing loss would prove to be a valuable clinical tool in testing these people. It would also serve as a confirmation of results obtained by conventional methods.

\section{Measurement of Acoustic Impedance}

The new clinical technique of acoustic impedance measurement at the tympanic membrane involves new concepts, terminology, and mathematical procedures which traditionally have not been emphasized in audiology training programs (Iily, 1973). Acoustic impedance represents the opposition by a surface to the flow of acoustic energy through that surface (Fulton and IIoyd, 1969). The acoustic impedance of the ear is dependent primarily upon the mobility of the middle ear system, which is dictated by the effects of three 
relative components: stiffness, mass, and resistanoo (Zwislocki, 1961). Stiffness is introduced by the eardrum, the ligaments and muscles of the middle ear, the volume of air in the middle ear, and the two cochlear windows. Mass is determined primarily by the weight of the ossicular chain. This is reduced to a minimum in normal ears by the balance of the ossicular chain around its axis of rotation. Resistance is contributed by the input impedance of the cochlea and the frictional movement of the ossicles (Zwislockl, 1963). Figure 5 demonstrates these sources of impedance.

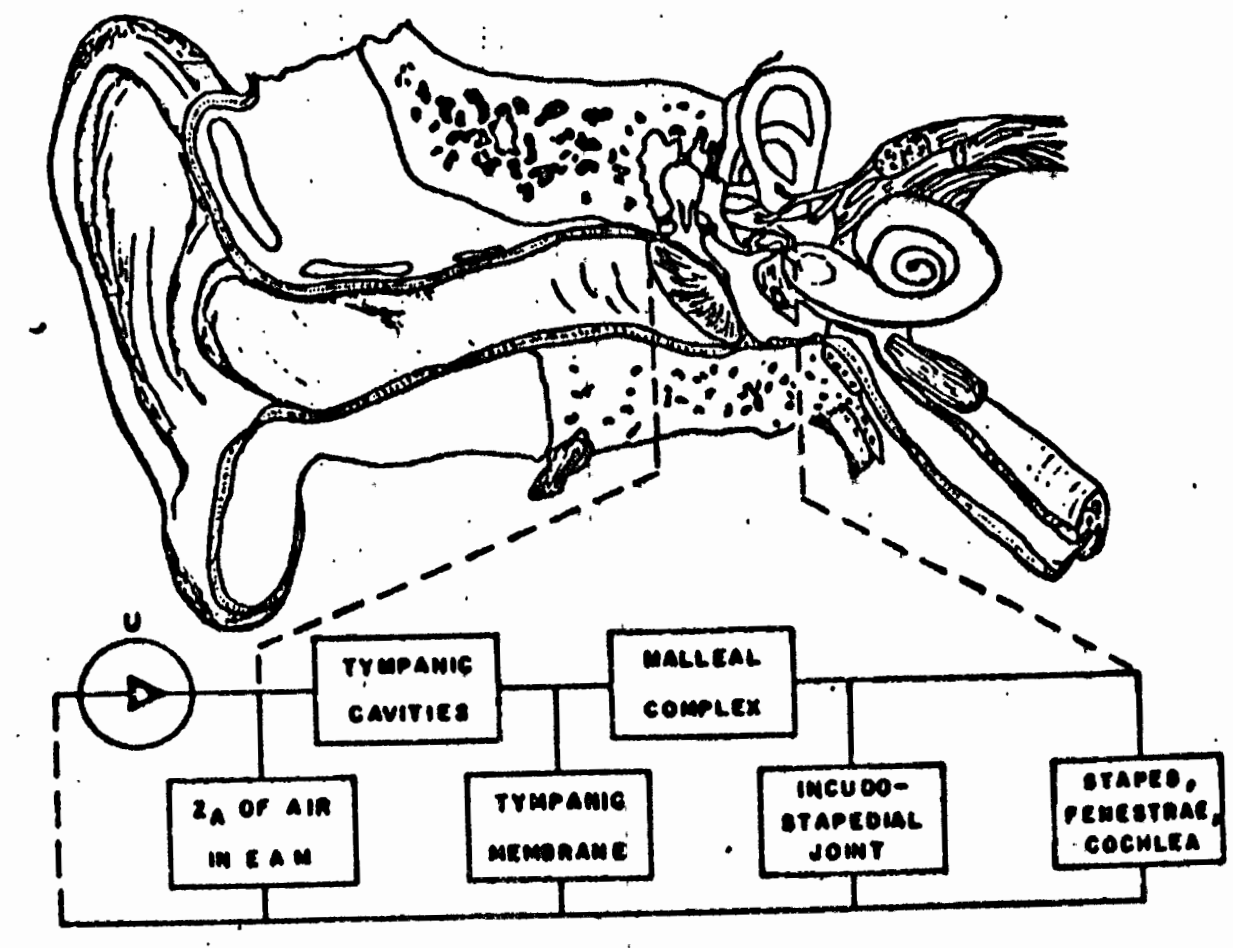

Figure 5. Peripherai auditory system and block diagram of air cavities and middle-ear structures that contribute to gcoustic impedance at plane of measurement in external auditory meatus (Iily, 1973). 
In a normal middle ear, contractions of either the stapedius or tensor tympani muscle produce a measurable change in acoustic impedance at the lateral surface of the tympanic membrane. This relation may be modified by middle ear infections, cochlear disease, and lesions that affect the trigeminal facial, or auditory nerves. The relation between threshold of audibility and threshold of acoustic reflex has been used as an objective measure of hearing sensitivity for young children (Jerger, 1970). It has also been used to provide an objective measure of recruitment for loudness. Contraction of the middle ear muscles will produce maximum impedance change at the tympanic membrane when the air pressure within the external auditory meatus is identical to the air pressure within the middle ear cavity (Jepsen, 1963).

Clinical acoustic impedance measurements may be classified as either static or dynamic. Static or absolute acoustic impedance measurements reflect directly the transmission characteristics of the middle ear: system and are reported in absolute physical units. Dynamic acoustic-impedance measurements may be reported in relative terms and measure dynamic changes in impedance caused by the acoustic reflex or the opening of the Eustachian tube (Lily, 1973). This study will be interested in dynamic measurements.

The study of impedance involves the analysis of the "opposition" offered by a system to the "flow" of energy. 
The term impedance may be defined as the complex ratio of a force-like quantity to a velocity-like quantity. Thus, the concept of impedance involves vector quantities and requires two numbers to specify it completely (Lily, 1973). The manufacturers of one of the latest electroacoustic meters note that the vectors of resistance and reactance, running at right angles to each other, combine into impedance precisely as the two legs of a right triangle "combine" in the hypoteneuse; namely, by the Pythagorean relationship $\left(Z=\sqrt{R^{2}+Y^{2}}\right.$, where $Z=$ impedance, $R=$ resistance, and $Y=$ reactance). The vector of reactance consists of two storage components, stiffness and inertia. Stiffness is identified as negative reactance and inertia as positive reactance. These two are 180 degrees out of phase so their net result is the algebraic sum of the two.

Berlin and Cullen (1975) gave the following formula for the total impedance of any mechanical system: $\mathbf{Z}=$ $\sqrt{R^{2}+\left(2 \pi f M-\frac{k}{2 \pi f}\right)^{2}}$ where $M=$ the mass of $a$; system, $k=$ the stiffness, and $R=$ the resistance factor.: The above formula demonstrates the frequency-dependent relationships between impedance, stiffness, and mass; mass reactance is greatest in the high frequencies, while stiffness reactance (elasticity) is greatest in the lows.

Conventional pure-tone audiometry has relied upon a comparison of pure-tone thresholds obtalized by measurement of the entire auditory system by ir conduction with 
measurement of the sensori-neural capacity by bone-conduction. As Feldman (1963) pointed out, this method only indirectly measures the function of the middle ear. The traditional air-bone gap frequently has been an inadequate method of measuring middle ear function and diagnosing impairment. Neither otoscopic nor audiometric examinations by this method have been entirely reliable in differentiating among a variety of middle-ear pathologies. Otoscopic examination depends upon the subjectivity of the examiner while audiometric examination relies upon the subjectivity of the patient (Zwislocki, 1963). It became increasingly apparent to clinicians in the field of audiological testing that a more objective, definitive method of measurement was necessary •

Webster (1919) introduced the concept of acoustic impedance, but it was directed towards musical instruments rather than clinical audiology. The work of Tröger (1930) is regarded as the first systematic study of acoustic impedance at the tympanic membrane. The first practical acoustic impedance bridge was built by Steward in 1926; this was followed by the acoustic bridge of Schuster in 1934. Metz (1946) demonstrated, using Schuster's bridge, that a variety of middle ear pathologies caused a change in impedance at the tympanic membrane. He was able also to detect contractions of the stapedius muscle (Zwislocki, 1963). 
The Metz bridge did not prove adequate for clinical practice; it was a large instrument which required complex didustment and computation. It did not compensate for individual differences in ear canal size, so gave variable results. Zwislocki (1961) modified the earlier bridge of Metz. The two most significant improvements were compensation for individual ear canal volume and a stable matching impedance which provided the examiner with a direct reading of compliance and resistance at the eardrum. Now, measurement of acoustic impedance at the tympanic membrane was "not just another audiological test," but constituted a "whole new field of investigation with an inherent new methodology" (Zwislocki, 1965).

An electronic counterpart of the Metz bridge was offered by Terkildsen and Nielsen in 1960. It provided a source of aix pressure which was continuously variable from a negative value through zero, to a positive value. This allowed the recording of tympanograms. All measurements were measured and calibrated in absolute figures, and a measure of complex impedance was obtained.

At the present time, two versions of the electroacoustic impedance metsr are in use clinically. The first nodel has greater diagnostic value than the TerkildsenNielsen model. It can be used for relative impedance measurement, absolute impedance measurement, and tymvanometry. It utilizes the principle that the volume of 
a hard-walled cavity can be determined by measuring the sound pressure level in the cavity when a pure tone is applied (Lamb, 1969). This machine measures acoustic impedance and its two components--resistance and reactance; it differs from the mechanical bridge in that, by employing only a single $220 \mathrm{~Hz}$. probe tone, it measures only the stiffness characteristics of a system. Relative impedance measurements may also be made. When the intra-tympanic muscles contract, compliance of the eardrum is altered, causing a disturbance of the balance meter (Lamb, 1969).

A second version of the electroacoustic impedance meter employs two probe tone frequencies $(220 \mathrm{~Hz}$, and 660 $\mathrm{Hz}$.$) and measures admittance of energy flow and its two$ components, conductance and susceptance. By employing two probe tones, it measures the mass component of reactance as well as the stiffness component. 
CHAPTER III

METHOD

Forty-three persons initial'y were selected to particlpate in this study as experimental subjects; however, sixteen were eliminated. In this group, an airtight seal could not be obtained on four subjects, and one subject decided not to participate. Seven persons were eliminated because of abnormal tympanograms, although conventional audiometric testing did not reveal an air-bone gap at either ear. Another four people yielded pure tone testing results indicative of conductive pathology. Ultimately, a total of 27 subjects were utilized for the study.

This clinical sample of 27 persons who were selected to serve as subjects for this study was drawn from a variety of sources, including the files of Project ARM (Auditory Rehabilitation Mob1le) of Portland State University, Portland City Housing Projects for Senior Citizens, the Volunteer Department of the United States Veteran's Hospital at Portland, Oregon, and private nursing homes for the elderly. in order to participate in the study, a subject was required to meet the following criteria: 1) sixty-five years of age or older, 2) a negative history of midale ear pathology, 3) a nonne tympanogram at each sar when tested on the 
electroacoustic impedance audiometer.

The ages of the subjects ranged from 64 to 83 years, with a median age of 73.2 years. Eleven of the subjects (26.8 percent) were males; thirty (73.2 percent) were females. See Appendix A for screening forms used in interviewing subjects for determining a negative history, of middle ear pathology.

A group of ten young adults ranging in age from 18 to 30 years with a median age of 22.7 years and zero hearing thresholds were selected to serve as controls for the study. This group also displayed normal middle ear function as determined by impedance audiometry.

\section{Instrumentation}

All impedance testing was conducted at Emanuel Medical Center in Portland, Oregon. An Electromedic Impedance Audiometer was employed for the study. The Electromedic Bridge is built in two sections, the impedance section (Model \#81) and the stimulus generator section (Model \#83). The headband assembly provides an impedance measurement earprobe on the side of the probe ear, and a TDH39 earphone provides stimulation on the contralateral side. Pure tone testing was conducted in a Suttle acoustic suite, using a Maico dual-channel audiometer, Model MA-24.

There are three major functional parts of the impedance system: 1) a probe-tone generator which emits a $220 \mathrm{~Hz}$. 
probe-tone, 2) a simple air pump, and an electromanometer for accurately measuring individual outer canal pressure, and 3) a sound pressure level and compliance sensing measurement system which monitors the sound pressure level of the residual probe tone in the outer canal. "Residual" in this sense refers to the energy which does not flow through the tympanic membrane into the middle ear (see Figure 6).

Air pressure and sound pressure are carefully controlled and induced in the outer canal and any changes are accurately measured. When 200 millimeters $\mathrm{H}_{2} \mathrm{O}$ pressure is introduced into the outer canal, the tympanic membrane and middle ear become rigid; the outer canal approximates a "hard-walled" cavity, and compliance is at a minimum. When pressure on both sides of the tympanic membrane is equal, a condition of maximum compliance and sound conduction and minimum impedance is obtained. A tympanogram, or graph of middle ear function, is obtained by continuously varying the air pressure in the outer canal from +200 millimeters $\mathrm{H}_{2} \mathrm{O}$ to -200 millimeters $\mathrm{H}_{2} \mathrm{O}$ and observing changes in the compliance. At both extremes, minimum compliance is noted. With stapedial muscle contraction, the tympanic membrane is pushed laterally and compliance is reduced, causing a recordable needle deflection of the Compliance Change Meter. The averages for the acoustic reflex have been found to be 82.2 $\mathrm{dB}$ for pure tones and $65.0 \mathrm{~dB}$ for white noise (Jepsen, (5): Metz, 1952). 


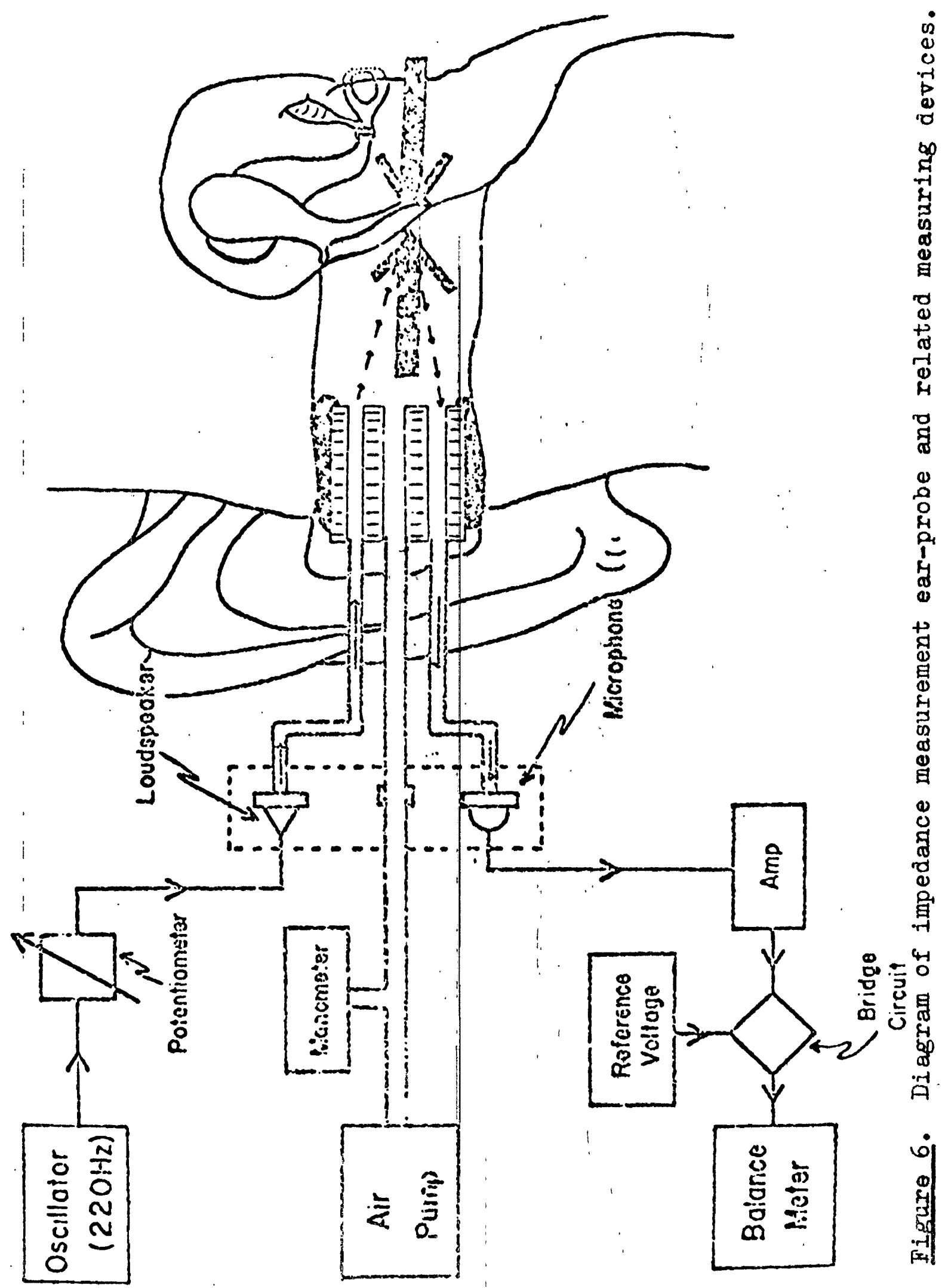


The stimulus section consists of a pure-tone generator of frequencies from $250 \mathrm{~Hz}, 500 \mathrm{~Hz},, 1000 \mathrm{~Hz},, 2000 \mathrm{~Hz}$, and $4000 \mathrm{~Hz}$. $(250 \mathrm{~Hz}$, and $4000 \mathrm{~Hz}$. were not used in this study); a broad-band noise generator with an attenuation range of $40 \mathrm{~dB}$ to $125 \mathrm{~dB}$ SPI; a low-pass noise generator with a cut-off frequency of $2600 \mathrm{~Hz}$; and a high-pass noise generator with a cut-off frequency of $2600 \mathrm{~Hz}$. All noise generators have an attenuation range of $40 \mathrm{~dB}$ to $125 \mathrm{~dB}$ SPI and an attenuation of $24 \mathrm{~dB}$ per octave (personal communication from Irwin Klar, Vice President American Electromedics Corporation, July, 1975). A stimulus interrupter switch initiates presentation of the selected stimulus and may be adjusted to provide a six second delay between action and stimulus presentation for reflex latency measure.

A physical calibration of the intensities of the various reflex eliciting signals is virtually impossible because of many variables. Among these are differences in the way different sound level meters measure broad band noise, calibration accuracy of pure tones, and frequency response variations in individual earphones (Jerger, 1974; Klar, 1975). Because of the many variables, a biological calibration was performed as follows: ten subjects (ages eighteen to thirty years) with normal hearing were tested both by pure tone audiometry and by impedance reflex measurements as described in the methods section of this report. The average of these scores were used as norms 
for the equipment. A physical calibration of the broadband noise was regularly performed, using a Bruel and Kjaer sound level meter, Model 1613.

\section{Test Procedure}

Prior to the individual audiological evaluation, each subject was given an otoscopic evaluation to determine the condition of the tympanic membrane and the presence or absence of cerumen. If excessive cerumen was present, the subject was instructed to have his ear cleaned before any further testing procedures were administered.

Impedance testing was conducted in a relatively quiet examining room with the subject seated in a chair facing the examiner. Prior to each evaluation, the procedure was explained to the subject, using an illustration of the inner, middle, and outer ear, and explaining how the probe was to be placed to secure a seal in the meatus. The subject was told to sit very quietly, to avoid swallowing, talking, or coughing, if possible. A headband was placed on the subject's head; an earphone was secured over the ear contralateral to testing, and a seal was obtained with the use of a soft rubber cuff in the test ear. Static compliance measurements were obtained at both ears. This was done by measuring the volume of air between the probe tip and the tympanic membrane when the membrane was clamped by a +200 millimeters $/ \mathrm{H}_{2} \mathrm{O}$ air pressure and subtracting the net value 
from that obtained at the point of maximum compliance of the tympanic membrane.

The second measurement obtained was tympanometry. A hermetic seal was effected in the ear canal; air pressure was varied from +200 millimeters $/ \mathrm{H}_{2} \mathrm{O}$ to $-200 \mathrm{millimeters} / \mathrm{H}_{2} \mathrm{O}$. The procedure produces a tympanogram, which depicts compliance changes in relation to air pressure variation in the ear canal. After tympanometry, the air pressure in the ear canal was reduced to the point of maximum compliance of the tympanic membrane, and reflex thresholds were obtained. Pure tones of $500 \mathrm{~Hz} ., 1000 \mathrm{~Hz} .$, and $2000 \mathrm{~Hz}$. were presented to the test ear. Presentation was administered in $5 \mathrm{~dB}$ steps until the lowest point that a 10 millimeter $/ \mathrm{H}_{2} \mathrm{O}$ deflection of the needle was noted. Following these measures, unfiltered white noise, low-pass white noise (below $2600 \mathrm{~Hz}$ ), and high-pass white noise (above $2600 \mathrm{~Hz}$ ) were presented in turn. Reflex thresholds of these different stimulus presentations were noted.

A third measurement obtained was pure-tone air and bone conduction thresholds. As previously indicated, none of the 27 experimental subjects or the 10 control subjects displayed an air-bone gap.

The results of conventional pure-tone audiometric data for each individual were then compared with results of the SPAR test (Sensitivity Prediction by the Acoustic Reflex). In cases of doubtful responses to pure tone 
testing, a speech reception threshold was obtained on the individual and used as a basis for comparison of results. The following formula (Jerger, 1974) was employed to determine the difference between thresholds of pure tones and white noise:

$$
\begin{aligned}
& a=\text { reflex threshold SPL for } 500 \mathrm{~Hz} . \\
& b=\text { reflex threshold SPI for } 1000 \mathrm{~Hz} . \\
& c=\text { reflex threshold SPI for } 2000 \mathrm{~Hz} . \\
& d=a+b+c / 3 \\
& e=\text { lowest reflex threshold SPI among a, b, and } c \\
& f=\text { reflex threshold SPI for BBN } \\
& 1=d-f(P T A-B B N) \\
& m=a-f(500-B B N) \\
& n=e-f(P T-B B N) \\
& D=\frac{1+m+n}{3}
\end{aligned}
$$

To predict slope of loss, the difference between thresholds for low-pass and high-pass filtered white noise was calculated. If the difference was zero or positive, a flat configuration was predicted. If the difference was in the range of -1 to -5 , a gradual slope was predicted. If the difference exceeded -5 , a steep slope was predicted (Jerger, 1974). Table III provides criteria for prediction of sensitivity 1oss.

The following criteria will be followed for categorizing losses:

Normal - Pure tone average less than $25 \mathrm{~dB} H L$ Mild-Moderate - Pure tone average $25 \mathrm{~dB}$ to $49 \mathrm{~dB}$ HL inclusive Severe - Pure tone average $50 \mathrm{~dB}$ to $84 \mathrm{~dB} \mathrm{HL}$ inclusive Profound - Pure tone average $85 \mathrm{~dB} \mathrm{HL}$ or more

The following criteria will be followed for categorizing slope of loss: 
TABLE III

CRITERIA FOR ASSESSMENT OF HEARING SENSITIVITY

\begin{tabular}{|c|c|c|c|}
\hline $\begin{array}{l}\text { Difference in reflex } \\
\text { thresholds pure tone } \\
\text { and broad band noise }\end{array}$ & $\begin{array}{l}\text { Phreshold levels } \\
\text { broad band noise i } \\
\text { SPI }\end{array}$ & $\begin{array}{l}\text { for } \\
\text { in }\end{array}$ & $\begin{array}{l}\text { Prediction of hear- } \\
\text { Ing sensitivity }\end{array}$ \\
\hline $\begin{array}{l}20 \text { or larger } \\
15-19 \\
15-19 \\
10-14 \\
\text { less than } 10 \\
\text { less than } 10 \\
\text { reflexes not } \\
\text { observed }\end{array}$ & $\begin{array}{l}\text { anywhere } \\
80 \mathrm{~dB} \text { or less } \\
81 \mathrm{~dB} \text { or more } \\
\text { anywhere } \\
89 \mathrm{~dB} \text { or less } \\
90 \mathrm{~dB} \text { or more }\end{array}$ & & $\begin{array}{l}\text { normal } \\
\text { normal } \\
\text { mild-moderate } \\
\text { mild-moderate } \\
\text { mild-moderate } \\
\text { severe } \\
\text { profound }\end{array}$ \\
\hline
\end{tabular}

Jerger (1974).

Flat - Difference between Ik and $4 \mathrm{~K}$ - less than $5 \mathrm{~dB}$

Gradual - Difference between $I K$ and $4 \mathrm{~K}-6 \mathrm{~dB}$ to $40 \mathrm{~dB}$

Steep - Difference between Ik and 4K - $40 \mathrm{~dB}+$

\section{Data Analysis}

Data relative to the geriatric sample and the control sample of young adults were analyzed as follows: 1) distribution of errors of assessment according to category of loss, 2) distribution of errors of slope of loss according to category, 3) distribution of errors of combined severity of loss and slope of loss according to category, 4) correlation of pure-tone averages of thresholds of hearing with reflex thresholds of stimuli, 5) means, standard deviations, and ranges of reflex thresholds of geriatric adults and young adults. 
A 2 test for statistical probability was performed for assessment of severity of loss, slope of loss, and combined severity and slope of loss to evaluate the possibllity of results happening by chance.

A one-tailed $t$ test of related means was performed to ascertain if there was a statistically significant difference in means of reflex thresholds between young, normalhearing adults and geriatric subjects.

Pearson Product-Moment Correlation Coefficients were calculated on the correlation between hearing threshold levels and reflex threshold levels for all types of stimuli used in this research project. 
CHAPTER IV

PRESENTATION OF RESULTS

The first question under investigation at the beginning of this study was: Will the determination of acoustic reflex thresholds be statistically valid in assessing magnitude of hearing loss among persons over sixty-five years of age who have no known otologic problems other than presbycusis? Table IV compares SPAR assessment results with actual results of conventional audiology for fifty-four aging ears. Of the twenty-four ears assessed as having normal hearing sensitivity, fourteen had audiometric results within normal limits ( $25 \mathrm{~dB}$ pure tone averages, or Iess); ten had hearing within mild-moderate limits ( $25 \mathrm{~dB}$ to $49 \mathrm{~dB} \mathrm{PTA}$ ); none had severe or profound losses. Of the twenty-seven ears assessed to have mild-moderate losses, sixteen actually yielded audiograms in this category; nine showed normal hearing; and two had severe losses. Of the three ears which were assessed to have profound hearing losses (lack of reflexes), one was shown to be normal and two were shown to have mild-moderate losses.

Table $\mathrm{V}$ displays the distribution of assessment errors for loss of hearing sensitivity. Accuracy of assessment was highest for mild-moderate ( 59.26 percent) and normal (58.34 
percent) categories, and the lowest for profound ( 0 percent). In only three ears were serious errors of assessment made, i.e., that of assessment of profound hearing losses. Of this group, none were profoundly deaf. A $Z$ test of statistical probability indicated that results of severity of loss were significant at the .01 level of confidence (Mendenhall, 1967).

TABLE IV

ASSESSMENT OF SEVERITY OF LOSS

\begin{tabular}{l|c|c|c|c}
\hline \multicolumn{1}{c|}{$\mathrm{N}=54$} & \multicolumn{3}{c}{ GERIATRICS } \\
\hline Actual & \multicolumn{3}{|c}{ Assessed } \\
\hline & Normal & Mild-Moderate & Severe & Profound \\
Normal & 14 & 9 & 0 & 1 \\
Mild-Mod. & 10 & 16 & 0 & 2 \\
Severe & 0 & 2 & 0 & 0 \\
Profound & 0 & 0 & 0 & 0 \\
Total & 24 & 27 & 0 & 3. \\
\hline
\end{tabular}

TABLE V

DISTRIBUTION OF ERRORS

ASSESSIEENT OF SEVERITY

\begin{tabular}{c|c|c}
\hline $\begin{array}{c}\mathrm{N}=54 \\
\text { Type of errors }\end{array}$ & Number of ears & Percentage \\
\hline None & 30 & $56 \%$ \\
Moderate & 21. & $39 \%$ \\
Serious & 3 & $5 \%$ \\
Total & 54 & $100 \%$ \\
\hline $\mathrm{Z}=3.23$ & & \\
$\alpha=.096$ & &
\end{tabular}



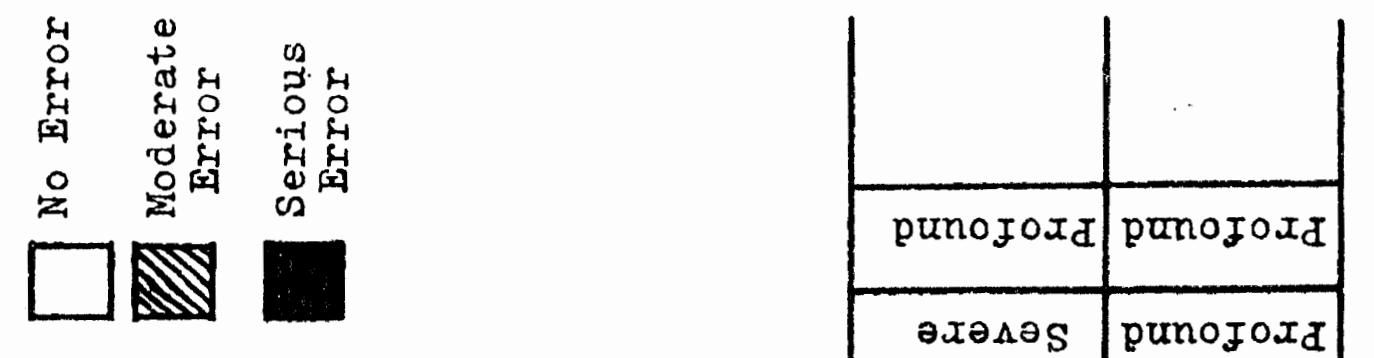

1
-1
0
0
1
0

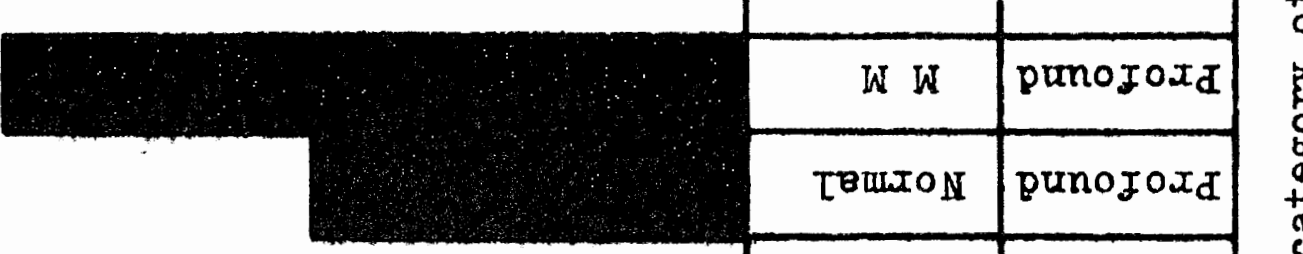

4

3

0

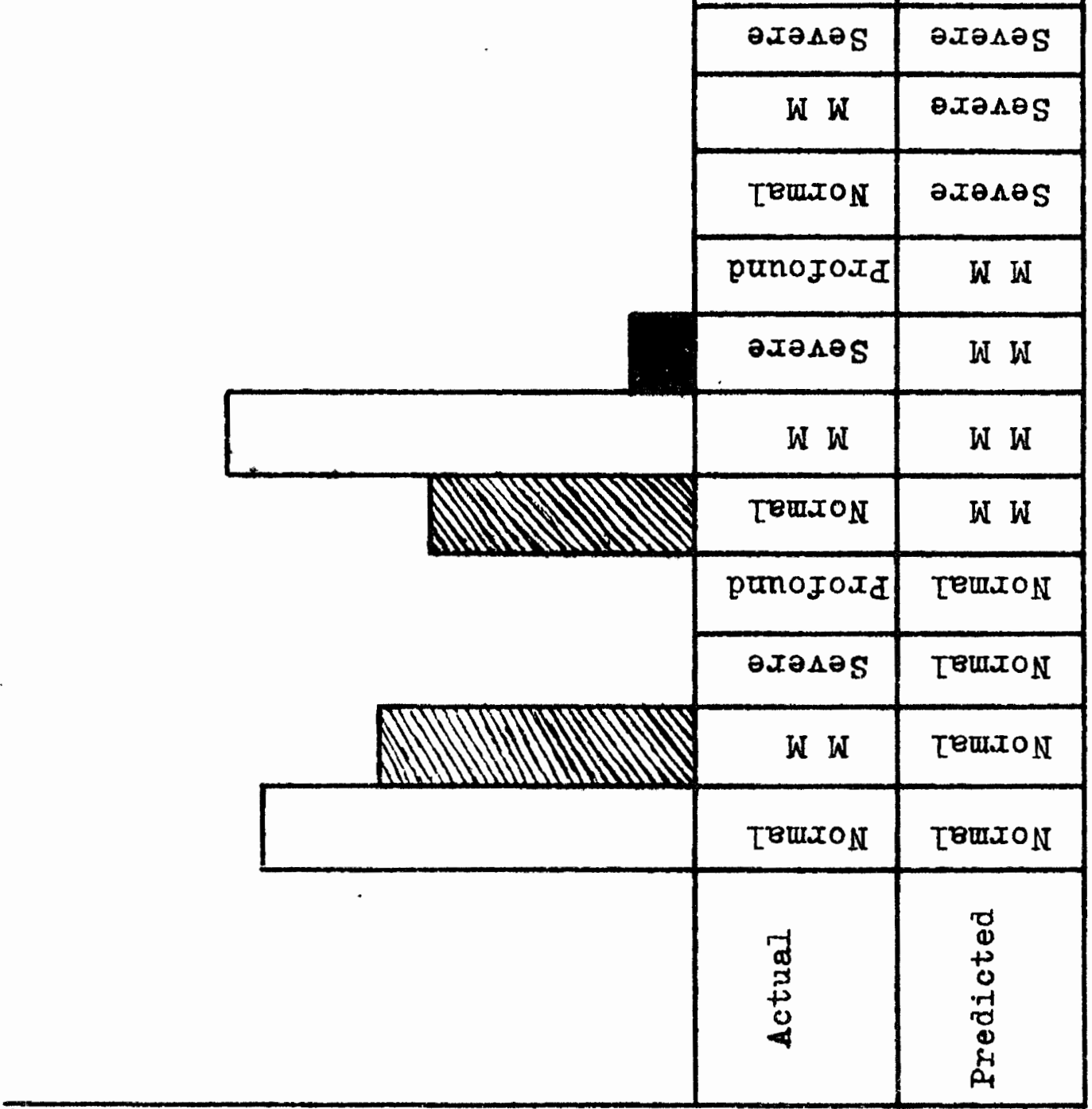

0
4
-
0
4
0
0
0
0
0
4
0
0
4
0

$\stackrel{0}{-r}$

出

d

\%

D.

H

궁

.-10

声

० 4

मी

$+4$

o 4

A

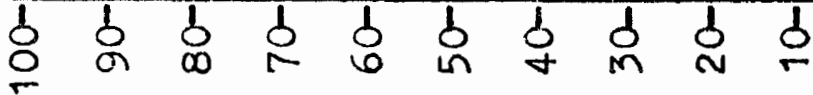

辛

dnoxง pəq0т̣paxd fo quasxad 
The second question under investigation was: Will acoustic reflex thresholds be statistically valid in assessing slope of loss among members of this sample? The results for slope of loss were not successful for the geriatric subjects, as displayed in Table VI. Assessment of slope of loss was also unreliable among the sample of young adults tested. In spite of regular physical calibration of low-pass and high-pass noise stimuli, reflex thresholds for these stimuli varied widely. Low-pass thresholds ranged from $70 \mathrm{~dB}$ to $105 \mathrm{~dB}$, and high-pass from $75 \mathrm{~dB}$ to $110 \mathrm{~dB}$, even though all subjects displayed absolutely normal $O d B$ hearing levels. It should be noted, however, that the largest percentage of errors (56 percent) were again moderate. Only 4 percent of errors of slope were serious. No loss configuration was assessed as flat or gradual among the steeply sloping losses (see Table VII).

TABIE VI

PREDICTION OF SIOPE OF LOSS

$N=45$

GERIATRICS

\begin{tabular}{l|c|c|c}
\hline Actual & \multicolumn{3}{|c}{ Predicted } \\
& Flat & Gradual & Steep \\
Flat & 1 & 2 & 2 \\
Gradual & 10 & 11 & 10 \\
Steep & 0 & 3 & 6 \\
Total & 11 & 16 & 18 \\
\hline
\end{tabular}


TABIE VII

DISTRIBUTION OF ERRORS

ASSESSMENT OF SIOPE

\begin{tabular}{c|c|c}
\hline \multicolumn{2}{c|}{$N=45$} & \\
\hline Type of error & Number of ears & Percentage \\
\hline None & 18 & $40 \%$ \\
Moderate & 25 & $56 \%$ \\
Serious & 2 & $4 \%$ \\
Total & 45 & $100 \%$ \\
\hline $\begin{array}{c}\mathrm{Z}=.3000 \\
\text { N }=.6368\end{array}$ & & \\
$\mathrm{P}=.3632$ & &
\end{tabular}

Table VIII compares the actual pure tone hearing loss slope categories of 44 aging ears with the slope of loss predicted from the SPAR data. An expected drop in the accuracy of assessment of the test occurred because of the poor assessment ability of the slope of loss. Table IX shows the distribution of errors. The majority of errors were moderate ( 77 percent); only 2 percent were severe. Persons with severe and profound losses were necessarily eliminated from this test because of lack of reflexes with high-pass noise stimulus.

The third question under investigation in this study. was: Will reflex thresholds of the older population prove 
TABIE VIII

ASSESSMENT OF BOTH SIOPE OF IOSS AND SEVERITY

\begin{tabular}{|c|c|c|c|c|}
\hline$N=44$ & \multicolumn{4}{|c|}{ GERIATRICS } \\
\hline Actual & \multicolumn{4}{|c|}{ Predicted } \\
\hline $\begin{array}{l}\text { Hearing Loss } \\
\text { Slope Category }\end{array}$ & Normal & $\begin{array}{l}\text { Normal } \\
\text { Sloping }\end{array}$ & Mild-Mod. & $\begin{array}{l}\text { Mild-Mod. } \\
\text { Sloping }\end{array}$ \\
\hline Normal & 0 & 2 & & 2 \\
\hline Normal Sloping & 8 & 2 & 4 & 2 \\
\hline Mild-Moderate & 2 & & & \\
\hline $\begin{array}{l}\text { Mild-Moderate } \\
\text { Sloping }\end{array}$ & & 9 & 5 & 7 \\
\hline Severe & & & 1 & \\
\hline Total & 10 & 13 & 10 & 11 \\
\hline
\end{tabular}

TABIE IX

DISTRIBUTION OF PREDICTIVE ERRORS ASSESSMENT OF SLOPE AND SEVERITY

\begin{tabular}{l|c|c}
\hline \multicolumn{2}{c|}{$\mathrm{N}=44$} & \\
\hline Type of error & Number of ears & Percentage \\
\hline None & 9 & $21 \%$ \\
Moderate & 34 & $77 \%$ \\
Severe & 1 & $2 \%$ \\
Total & 44 & $100 \%$ \\
\hline
\end{tabular}

$$
\begin{aligned}
Z & =.91 \\
\infty & =.8289 \\
P & =.1711
\end{aligned}
$$

to be statistically different from those of the young adult control group? Table X presents means, standard deviations, 
TABILE X

MEANS, STANDARD DEVIATIONS, RANGES

OF REFLEX THRESHOLDS ( $Q B$ )

\begin{tabular}{|c|c|c|c|c|c|c|c|}
\hline \multicolumn{8}{|c|}{ GERIATRICS } \\
\hline & $500 \mathrm{~Hz}$. & $1 \mathrm{~K} \mathrm{~Hz}$ & $2 \mathrm{~K} \mathrm{~Hz}$ & PTA & Wht. N & IPN & HPN \\
\hline $\begin{array}{l}\bar{X} \\
S D \\
R\end{array}$ & $\mid \begin{array}{c}105.64 \\
11.02 \\
81-126\end{array}$ & $\begin{array}{c}99.50 \\
8.23 \\
76.5-131\end{array}$ & $\begin{array}{c}104.19 \\
10.86 \\
88.5-133.5\end{array}$ & $\begin{array}{c}102.68 \\
4.12 \\
82-123\end{array}$ & $\begin{array}{l}93.43 \\
11.02 \\
75-115\end{array}$ & $\begin{array}{l}97.65 \\
11.37 \\
75-125\end{array}$ & $\begin{array}{l}103 \cdot 30 \\
23.25 \\
85-115\end{array}$ \\
\hline \multicolumn{8}{|c|}{ YOUNG ADULTS } \\
\hline & $500 \mathrm{~Hz}$. & $1 \mathrm{~K} \mathrm{~Hz}$. & $2 \mathrm{~K} \mathrm{~Hz}$ & $\mathrm{PTA}$ & Wht. $N$ & IUPN & HPN \\
\hline $\begin{array}{l}\bar{X} \\
\text { SD } \\
\mathrm{R}\end{array}$ & $\begin{array}{c}96.25 \\
6.17 \\
91-116\end{array}$ & $\begin{array}{c}93.5 \\
4.97 \\
86.5-101\end{array}$ & $\begin{array}{c}94.5 \\
7.0 \\
83.5-103.5\end{array}$ & $\begin{array}{c}93.3 \\
3.59 \\
81-103\end{array}$ & $\begin{array}{l}71.5 \\
5.36 \\
70-90\end{array}$ & $\begin{array}{l}89 \cdot 0 \\
14 \cdot 15 \\
70-105\end{array}$ & $\begin{array}{l}92.0 \\
14.59 \\
75-110\end{array}$ \\
\hline
\end{tabular}

and ranges of reflex thresholds for young, normal-hearing persons and geriatric subjects. Thresholds for the older population were from $6 \mathrm{~dB}$ to $22 \mathrm{~dB}$ greater than they were for young normala. The greatest difference in levels was noted for white noise, with significant differences also observed for low-pass and high-pass filtered noise.

Figures 8 and 9 demonstrate the differences in ranges and standard deviations between young adults and geriatrics. It is apparent that the ranges of reflex thresholds are far greater than in the young population.

Table XI displays results of a one-tailed t test of related means (Bruning, 1968) comparing reflex threshold 

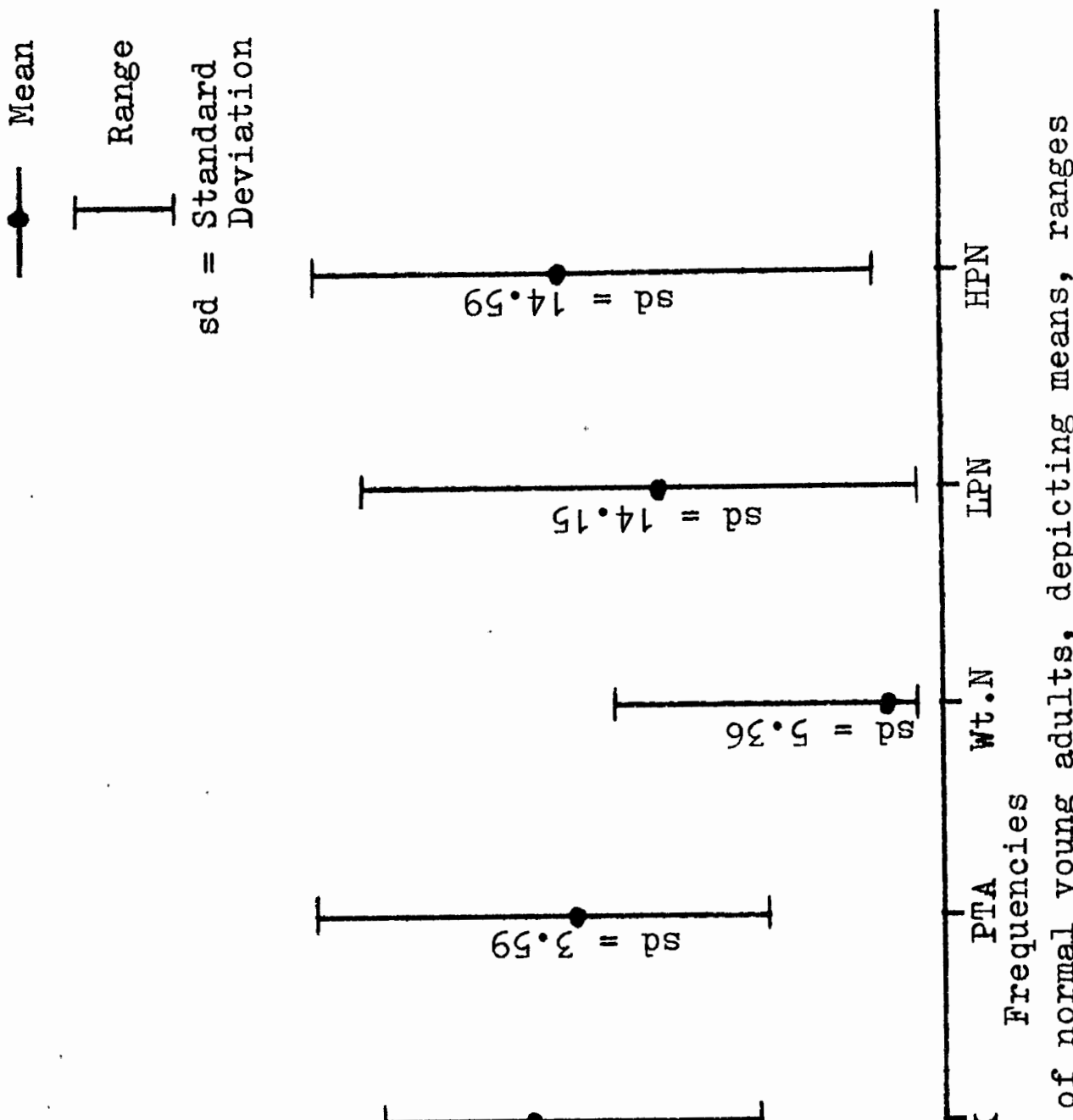

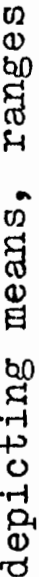

$$
\begin{aligned}
& \text { 1 } \\
& 0
\end{aligned}
$$
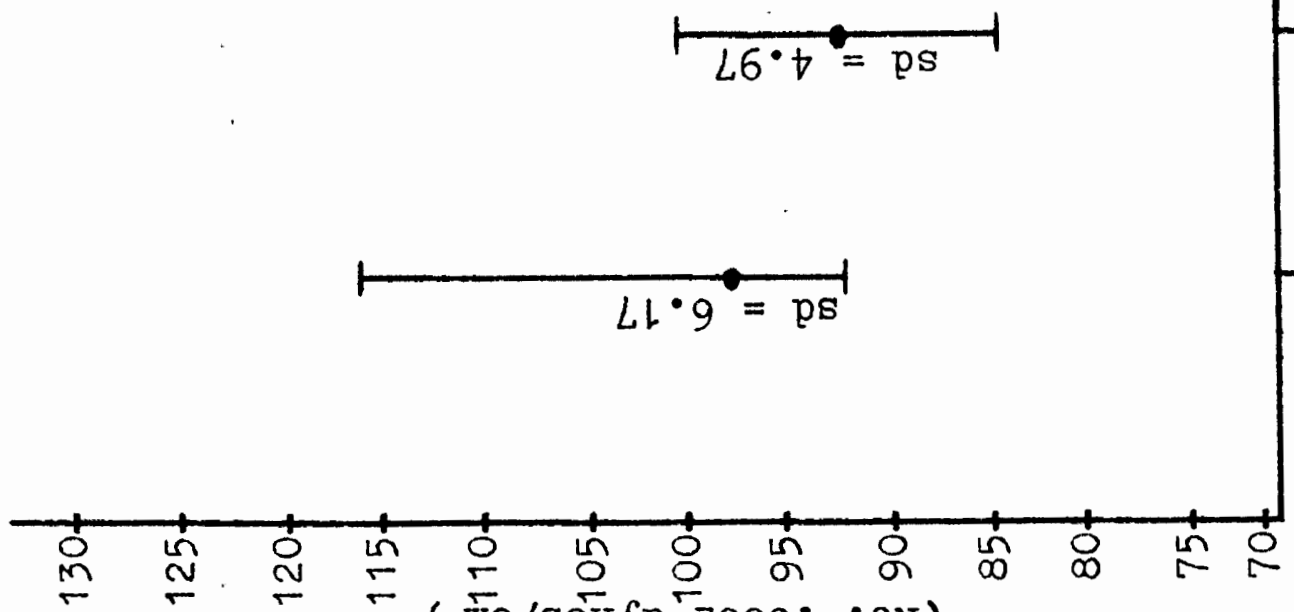
$\left(2^{\overline{40} / s \partial u \Lambda p} 2000^{\circ} \cdot \partial \mathrm{d}\right)$

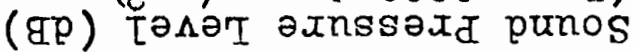



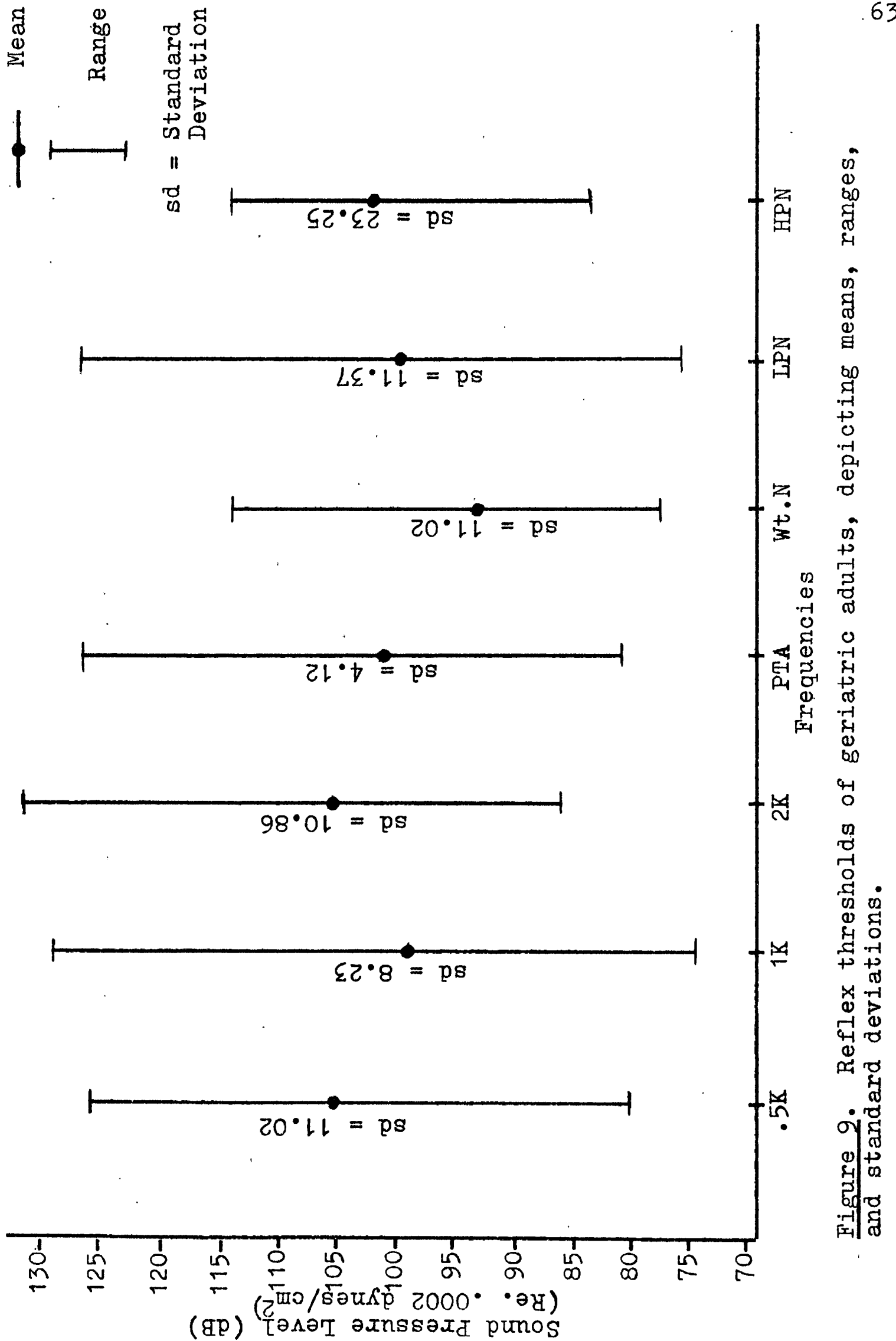
TABLE XI

$t$ VALUES--NORMALS AND GERIATRICS REFIEX THRESHOLD IEVELS

\begin{tabular}{l|c|c}
\hline \multicolumn{1}{c|}{ Stimulus } & $t$ Value & Level of Confidence \\
\hline $500 \mathrm{~Hz}$ & 3.85 & .005 \\
$1 \mathrm{~K} \mathrm{Hz.}$ & 3.09 & .005 \\
$2 \mathrm{~K} \mathrm{~Hz}$. & 3.73 & .005 \\
PTA & 9.11 & .005 \\
White Noise & 5.46 & .005 \\
Low-Pass Noise & 2.73 & .005 \\
High-Pass Noise & 2.07 & .025 \\
\hline
\end{tabular}

levels of young adults and geriatrics. Significant differences were revealed for all stimuli beyond the .005 level of confidence except for high-pass white noise.

Additional information regarding the results of this study are presented in Table XII which demonstrates the correlations calculated on the relationships between thresholds of hearing data and reflex thresholds for the various stimuli. Pearson Product-Moment Correlation Coefficients Indicated the relationship between pure tone average of the speech frequencies and reflex thresholds were statistically significant, while those between reflex thresholds and thresholds of hearing at $4000 \mathrm{~Hz}$. and $8000 \mathrm{~Hz}$. were not. These results suggest that the acoustic reflex is a mechanism which is triggered by neural activity in the lower frequency area of the cochlea, and thus serves to attenuate low-frequency sounds to a greater extent than those of high-frequency. 
TABLE XII

CORRELATIONS BETWEEN THRESHOIDS

AND REPLEX IEVELS

\begin{tabular}{|c|c|c|c|c|}
\hline $\mathrm{N}$ & & $r^{*}$ & Sig. Values & Significance \\
\hline $\begin{array}{l}44 \\
35 \\
51 \\
30 \\
51 \\
51 \\
45 \\
51 \\
51 \\
50\end{array}$ & $\begin{array}{l}4 \mathrm{~K} \text { and High-Pass Wht. Noise } \\
8 \mathrm{~K} \text { and White Noise } \\
4 \mathrm{~K} \text { and White Noise } \\
8 \mathrm{~K} \text { and High-Pass Wht. NoIse } \\
\text { PTA and Reflex at } 1 \mathrm{~K} \\
\text { PTA and Low-Pass Wht. Noise } \\
\text { PTA and High-Pass Wht. Nolse } \\
\text { PTA and White Noise } \\
\text { PTA and Reflex at } 500 \mathrm{~Hz} \text {. } \\
\text { PTA and Reflex at } 2 \mathrm{~K}\end{array}$ & $\begin{array}{l}.02 \\
.08 \\
.17 \\
.13 \\
.78 \\
.65 \\
.44 \\
.37 \\
.75 \\
.35\end{array}$ & $\begin{array}{r}.10=.2428 \\
.10=.2573 \\
.10=.2428 \\
.10=.2573 \\
.001=.4433 \\
.001=.4433 \\
.01=.3421 \\
.01=.3541 \\
.001=.4433 \\
.02=.3218\end{array}$ & $\begin{array}{l}\text { Not Sig. } \\
\text { Not Sig• } \\
\text { Not Sig• } \\
\text { Not Sig. } \\
\text { Sig• } \\
\text { Sig• } \\
\text { Sig• } \\
\text { Sig• } \\
\text { Sig• } \\
\text { Sig. }\end{array}$ \\
\hline
\end{tabular}

*Pearson's Product-Moment Correlations.

\section{Discussion of Results and Implications}

\section{Clinical Implications}

The results of this research were gratifyingly satisfactory for assessment of loss of hearing sensitivity in the geriatric population. The percentage of correct assessments was 56 percent; this compares very favorably with Jerger's 60 percent. The percentage of moderate errors (one scale divergence from actual) was 39 percent as compared to 36 percent in Jerger's studies. The percentage of serious errors (two scale divergences from actual) was 5 percent; Jerger found 4 percent. These results were very significant in view of the many variables which enter into the hearing sensitivity of the presbycusic subject. Among these 
variables are recruitment, high-frequency hearing Ioss, variations in ear canal size, and conductive components. The error in prediction of profound losses may be due to the fact that, in any group of normal hearing persons, there appears to be a very small percentage from whom an acoustic reflex cannot be elicited. This is a probable weakness of the SPAR test for individual patients. A very encouraging result of this testing was that 39 percent of the errors of assessment were only moderate (one scale from actual hearing). As a result, no person with a severe loss was predicted to have normal hearing. This could be a very serious mistake in a very old or a very young population.

Static compliance measures were calculated for all subjects on which tympanometry was performed. They were calculated by subtracting the volume measurement taken at +200 millimeters $/ \mathrm{H}_{2} \mathrm{O}$ air pressure in the external meatus from that taken at the point of maximum compliance of the tympanic membrane. The process eliminates the external ear canal volume and gives a value representative of the amount of mobility of the middle ear in cubic centimeters. Normal static compliance values range between $.30 \mathrm{cc}$. to $1.60 \mathrm{cc}$. Stiff systems may demonstrate compliance values of less than $.30 \mathrm{cc}$. and flaccid systems greater than $1.60 \mathrm{cc}$. (Jerger, 1972). Of the 51 geriatric ears on which this measure was taken, ten exhibited static compliance not within these limits. Six suggested flaccid middle ears; 
four gave results which indicated stiffness. This measure was used as a check on normal middle ear function in the study

Four of the original forty-three subjects ( 9.2 percent) were discovered with abnormal tympanograms which were accompanied by significant air-bone gaps. These people were urged to seek medical assistance. One might question the extent to which long-neglected, medically-correctible, hearing problems may exist in the older population, especially in view of the fact that none of these individuals acknowledged prior otologic symptoms.

The SPAR test provides a wholly new, objective method of assessing hearing sensitivity, and on the basis of this study, should prove very valuable as a means of checking the validity of pure tone thresholds in aging subjects.

Tympanometry is now becoming a vital, routine practice in most audiology clinics. Occasionally an ear may be encountered which is difficult to seal, but this is a very small segment of the geriatric population. The entire process can be completed in twenty minutes; this proves to be a wise investment of time in terms of the additional information which it provides.

\section{Theoretical Implications}

In the geriatric group, eight persons were found to 
have hearing sensitivity within normal range, based upon the average of pure tone thresholds at $500 \mathrm{~Hz}, 1000 \mathrm{~Hz}$, , and $2000 \mathrm{~Hz}$. and no evidence of noise-induced hearing loss. AlI of the "normal" sixteen ears displayed higher reflex levels for both average pure tone thresholds $(X=101.4 \mathrm{~dB})$ and white noise $(X=90.4 \mathrm{~dB})$ than did the group of normal young adults $(X=93.3 \mathrm{~dB} P T A)$ and $(X=71.5 \mathrm{~dB})$ white noise. While still within normal limits, the older group of normal hearing persons had pure tone averages of $9.9 \mathrm{~dB}$ higher than those of the young adults. This may explain the $10 \mathrm{~dB}$ difference in the mean PTA reflex thresholds, but not the $21 \mathrm{~dB}$ difference in those for white noise. A very small group (four people) exhibited normal hearing in the high frequency area, but more high-pass noise energy was required to elicit reflexes than for young normals with similar thresholds. It appears that neural changes occur within the aging auditory system even in the presence of normal peripheral hearing sensitivity. This tends to confirm the theory (Scharf and Heliman, 1966; Jerger, 1974) that the critical bands widen and decrease in numbers in the aging process.

An interesting group consisted of persons who displayed abnormal tympanograms in the absence of air-bone gaps. Five persons of the original forty-three (11.6 percent) of the group fell into this category and provided further confirmation of Goodhill's theory (1969) that presbycusis involves an aging process in ligaments, muscles, and 
connective tissues, and may include mechanical lesions which involve the tympanic membrane and the ossicular chain movements.

One seventy-one year old female subject was found to have pure tone averages of $2 d B$ and $3 d B$. This serves to emphasize that chronological aging and biological aging are two separate entities, and contradicts Glorig's and Nixon's hypothesis (1962) that progress of hearing loss as a function of age can be-described and predicted quite accurately. 
CHAPTER $\mathrm{V}$

SUIMIMARY AND IMPIICATIONS

The purpose of this study was to investigate the use of the SPAR (Sensitivity Prediction by the Acoustic Reflex Test) on a sample of older adults who had negative otologic histories... Twenty-seven subjects ranging in age from-sixtyfour to eighty-three years of age (54 ears) were chosen as subjects. A normal-hearing, young adult group, ranging in age from eighteen years to thirty years of age, served as controls. Reflex threshold levels were obtained, using $500 \mathrm{~Hz} ., 1000 \mathrm{~Hz}$, , and $2000 \mathrm{~Hz}$. pure tone and noise stimuli. Assessment_of hearing_lass was calculated..on the difference..... between measures to ascertain hearing loss category and slope of loss according to a formula developed by Jerger (1974).

The following conclusions were made on the basis of data collected in this investigation:

1). The SPAR test was significant in assessing hearing sensitivity levels among the sample of geriatric subjects.

2) The SPAR test was not statistically significant in assessing slope of loss in this sample of geriatric subjects. 
3) Reflex thresholds were consistently higher for aging than for a sample of young adults with normal hearing. This was true even among elderly subjects with average pure tone thresholds in the normal range.

4) A significant portion of this carefully screened older adult sample displayed abnormal midale-ear function (as measured by tympanometry) in the absence-of conventional audiometric-indications. of this.

5) A significant portion of this older adult sample provided audiometric evidence of middle-ear pathology •

\section{Implications for Further Research}

Very little research has been conducted in the area of tympanometry for the older, hearing-impaired patient. This study was limited to a relatively small number of subjects and a large percentage of female subjects. Further research possibilities suggest using this technique on larger numbers of subjects and on a sample of male geriatric subjects. More research is also needed to establish reliability of aspessment of slope of loss on a young, sensorineural population.

An additional field of research lies in the investigation of the critical band patterns in the aging process and 
the influence of this patterning on the older subject's perception of speech. A shift of the critical band patterns in the high-frequency area of the basilar membrane may tend to impair a vital link in the speech discrimination process and cause distortion of the speech signal. This is a field of research virtually untouched at the present.time and one which offers exciting research possibilities for the future. 


\section{REFERENCES}

Bekesy, G. V., "Zur Physik des Mittelohres and uber das Horen bei fehlerhafter Trommelfell." Akustik Zeitschrift, 13-23, (1936).

, and Rosenblith, W. A., "The Mechanical Properties of the Ear." Handbook of Experimental Psychology, S. S. Stevens, Editor, John Wiley and Sons, New York, (1951).

$(1960)$

Experiments in Hearing, McGraw Hill Co., New. York,

Berlin, C. A., and Cullen, J. K. Jr., "The Physical Bases of Impedance Measurement." In Handbook of Clinical Impedance Audiometry, James Jerger, Editor, American Electromedics Corporation; Dobbs Ferry, New York, $(1975)$.

Borg, E., "A Quantitive Study of the Effect of the Acoustic Stapedius Reflex on Sound Transmission Through the Middle-Ear of Man." Acta-Otolaryngologica, Vol. 66, p. 461-472, (1968).

, "On the Neuronal Organization of the Acoustic Middie-tar Reflex. A Physiological and Anatomical Study." In Brain Research, Vol. 49, Elsevier Scientific Publishing Co., Amsterdam, Netherlands, (1973).

Bruning, J. I., and Kentz, B. I., Computational Handbook of Statistics, Appendix F, p. 229, Scott Fressman Co., Glenview, Illinois, (1968).

Dallos, P., "Dynamics of the Acoustic Reflex: Phenomenological Aspects." Journal of Acoustical Society of America, Vol. $36, \mathrm{p} .217 \overline{5-2183}$, (1964).

The Auditory Periphery, Academic Press, New York, Lond on, $(1973)$.

De Boer, E., "Measurement of the Critical Band-Width in Cases of Perception Deafness." Proceedings of III International Congress of Acoustics, Vol. $1, \frac{1}{\mathrm{p}} . \frac{11}{10} 0-$ 102, cited in Foundations of Moderm Auditory Theory, J. Tobias, Editor, Academic Press, New York, (1970). 
Djupesland, G., "Intra-Aural Muscular Reflexes Elicited by Air Current Stimulation of the Extermal Ear." Actaotolaryngologica, Vol. 54, p. 143-153, (1962).

Feldman, A. S., "Impedance Measurements at the Eardrum as an Aid to Diagnosis." Journal of Speech and Hearing Research, Vol. 6, p. 315-317, (1963).

Fex, J., "The Olivo-Cochlear Feedback Systems." In SensoriNeural Hearing Processes and Disorders, A. Bruce Graham, Editor, Iittle Brown Co., Boston, Massachusetts, (1967).

Fleming, N., "Resonance in the External Auditory Meatus." Vol. 143, (1939).

Fletcher, H., "Auditory Patterns." Review of Modern Physics, Vol. 12, p. 47-65, (1940).

, Speech and Hearing in Communication, Van Nostrand, Princeton, New Jersey, (1953).

, and Riopelle, A. J., "Protective Effect of the Acoustic Reflex for Impulse Noises." Journal of the Acoustical Society of America, Vol. 32:3, March, 1960, p. 401-404.

Forbes, A., and Sherrington, C., American Journal of Physiology, Vol. 35, p. 367, (1914).

Fulton, R., and LIoyd, I., Audiometry for the Retarded: With Implications for the Difficult to Test, William and wilkins, Baltimore, (1969).

Gaecek, R. A., "Neuroanatomy of the Auditory System." In Foundations of Modern Auditory Theory, Vol. II, Jerry Tobias, Editor, Academic Press, New York, London, (1972).

Gaeth, J., "A Study of Phonemic Regression in Relation to Hearing Loss." Unpublished Doctoral Dissertation, Northwestern University, (1948).

Galambos, R., and Rupert, A., "Action of the Middle-Ear Muscles of Normal Cats." Journal of the Acoustical Society of America, Vol. 31, p. 349-355, (1959).

Gassler, G., "Uber die Horschswelle fur Schallereignisse mit Verschieden breitem Frequenzspektrum." Acustica, Vol. 4, p. 408-414, (1954). 
Gerard, R. W., "Aging and Organization." In Handbook of Aging and the Individual, James E. Birren, Editor, University of Chicago Press, (1967).

Glorig, A., and Davis, H., "Age, Noise, and Hearing Ioss." Annals of Otology, Rhinology, and Laryngology, VoI. $70, \mathrm{p} \cdot 556-571,(1961)$. Age." and Nixon, J., "Hearing Loss as a Function of

Goodhill, V., "Bilateral Malleal Fixation and Conductive Presbycusis." Archives of Otology, Vol. 90, p. 759$764,(1969)$.

Hammerschlag, V., "Die Lage des Reflexcentrums fur den Musculus Tensor Tympani." Archives Ohrenheila, p. 157-160, (1901).

Hinchcliffe, R., "The Anatomical Locus of Presbycusis." Journal of Speech and Hearing Disorders, Vol. 27, p. 301-310, (1962)

"Aging and Sensory Thresholds." Journal of Gerontology, Vol. 17, p. 45, (1962).

Jepsen, O., "Middle-Ear-Muscle Reflexes in Man." In Modern Developments in Audiology, James Jerger, Editor, Academic Press, New York, (1963).

Jerger, J., and Tillman, T. W., and Peterson, J. I., "Masking by Octave Bands of Noise in Normal and Impaired Ears." Journal of the Acoustic Society of America, Vol. 32, p. 311-324, (1970).

, "Clinical Experience With Impedance Audiometry." Archives of otolaryngology, Vol. 92, p. 311-324, (1970).

, "Predicting Hearing Loss from the Acoustic Reflex." Journal of Speech and Hearing Disorders, Vol. 39:1, p. 11-22, $(1974)$.

Johnson, I. C., and Hawkins, J. E., "Sensory and Neural Degeneration With Aging, as Seen in Microdissections of Human Inner Ear." Annals of otology, Rhinology, and Laryngology, Vol. 81, p. 179-183, (1972).

Kimura, R., and Wersall, J., "Texmination of the OlivoCochlear Bundle in Relation to the Outer Hair Cells of the Organ of Corti in the Guinea Pig." Actaotolaryngologica, Vol. 55, p. 24-39, (1955). 
Kirakae, I., The Structure and Function of the Middle Ear, University of Tokyo Press, Tokyo, Japan, (1960).

- Sato, R., and Shitara, T., "A Study of Hearing in Advanced Age." Laryngoscope, Vol. 74, p. 2, (1964).

Klar, I., Personal Communication, July, 1975.

Klockhoff, I., and Anderson, H., "Reflex Activity in the Tensor Tympani Muscle Recorded in Man." ActaOtolaryngologica, Vol. 51-52, (1960).

Konnigsmark, B. W., "Aging of Cells and Structures." International Audiology, Vol. 8:2, p. 191-196, (1969).

Krmpotic-Nemanic, J., "Presbycusis and Retrocochlear Structures." International Audiology, Vol. 8, p. 210, (1969).

Lamb, I. E., and Norris, T. W., "Acoustic Impedance Measurements." In Audiometry for the Retarded, R. T. Fulton and I. L. Lloyd, Editors, Williams and Wilkins, Baltimore, (1969).

Lightfoot, C., Carhart, R., and Gaeth, J. H., "Efficiency of Impaired Ears in Noise; A Threshold for Pure Tone and for Speech." U.S. Air Force School of Aviation Medical Report \#4, Project 21, 1203.

Lily, D. J., "Measurement of Acoustic Impedance at the Tymt panic Membrane." In Modern Developments in Audiology, James Jerger, Editor, Academic Press, New York, (1973).

Iindsay, J. R., Kobrak, H., and Perlman, H. B., Archives of Otolaryngology, Vol. 23, p. 671, (1936).

Lorente de No, R., "Anatomy of the Eighth Nerve. General Plans of Structure of the Primary Cochlear Nuclei." Laryngoscope, Vol. 43, p. 327-350, (1933).

Makishama, K., "Clinicopathological Studies in Presbycusis: Central and Cochlear Findings." Ctology Fukuoka. Supp. 13, Vol. 183, (1967).

Martin, M. C., "Critical Bands in Sensori-Neural Hearing Loss." Scandinavian Audiology, Yol. 3, p. 133-140, (1974).

Niassion, J., and Albe-Fessard, D., "Caracteristiques differentielles des responses zux stimulations sensorielles des deux parties du Noyan rouge." C.R. Academie Scientific, Vol. 268, Paris, France, $(1959)$. 
Mendenhall, W., Introduction to Probability and Statistics, Wadsworth Publishing Company, Belmont, California, (1967).

Metz, 0., "The Acoustic Impedance Measured on Normal and Pathological Ears." Acta-otolaryngologica, Supplement \#63, (1946).

Moller, A. R., "Acoustic Reflex in Man." Journal of the Acoustic Society of America, Vol. 34, p. 1524-1534, $(1962)$.

, "The Middle Ear." In Foundations of Modern Auditory Theory, Vol. II, Jerry Tobias, Editor, Academic Press, New York and London, (1972).

Naunton, R. F., "Presbycusis." In Otolaryngology, VoI. II, M. Paparella and D. A. Shumrich, Editors, W. B. Sanders Company, Philadelphia, (1973).

Niese, H., "Subjektive Messung der Lautstacke van Bandpassrauchen." Vol. 69, p. 1-17, (1960).

Nixon, J., Gloric, H., and High, W., "Changes in Air-andBone Conduction Thresholds as a Function of Age." Annals of Otology, Rhinology, and Laryngology, Vol. 74, p. 288-298, (1962).

Northern, J. I., Lecture Notes, Seminar on Tympanometry, Vancouver, B.C., (1974).

Okomato, M., Sato, M., and Kirakae, I., "Studies of the Acoustic Reflex." Annals of ot.ology, Rhinology, and Laryngology, Vol. 63, p. 950, (1954).

Perlman, H. B., and Case, T. J., "Latent Period of the Crossed Stapedius Reflex in Man." Annals of Otology, Rhinology, and Laryngology, Vol. 48, p. 663-675, (1939).

Rasmussen, G. I., "The Olivary Peduncle and Other Fiber Projections of the Superior Olivary Complex." Journal of Comparative Neurology, Vol. 84, p. 141-219, (1946). Bundie." Jurther Observations on the Efferent Cochlear
Journal of Comparative Neurologx, Vol. 99, p. 61-74, (1953). Cochiear Nucleus," In Neural Mechanisms of the Auditory and Vestibular Systems, p. 105-115, Charles C. Thomas, Springfield, Illinois, (1960). 
Rasmussen, G. I., "Anatomic Relations of the Ascending and

Descending Auditory System." In Neurological Aspects of Auditory and Vestibular Disorders, W. S. Field and B. R. Alford, Editors, Charles Thomas, Springfield, Illinois, p. 5-19, (1964).

"Efferent Connections of the Cochlear Nucleus." In Sensori-Neural Hearing Processes and Disorders, A. Bruce Graham, Editor, Little Brown Co., Boston, Massachessets, (1967).

Rittmanic, P. A., "Pure-Tone Masking by Narrow Bands in Normal and Impaired Ears." Jourmal of Auditory Research, Vol. 2, p. 287-302, (1962).

Rosen, E., Plester, D., El-Mofty, A., and Rosen, H., "HighFrequency Audiometry in Presbycusis." Archives Otolaryngology, Vol. 79, p. 18-32, (1964).

Rupp, D., "Understanding the Problems of Presbycusis: An Overview on Hearing Loss Associated With Aging." Geriatries, Vol. 25:1, p. 100-107, (1970).

Sataloff, J., Vassalo, I., and Menduke, H., "Presbycusis: Air-and-Bone-Conduction Thresholds." Laryngoscope, Vol. 75, p. 889-901, (1965).

Scharf, B., and Hellman, R. P., "A Model of Loudness Summation Applied to Impaired Ears." Jourmal of

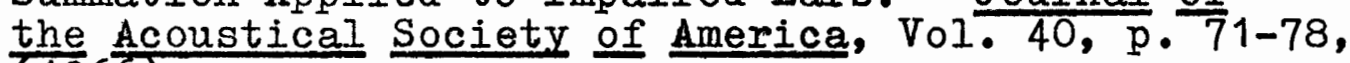
$(1966)$.

, "Critical Bands." In Foundations of Modern Auditory Theory, Vol. I, Jerry Tobias, Editor, Academic Press, New York, (1970).

Schuknecht, H. F., "Presbycusis." Laryngoscope, Vol. 65, p. 402-419, (1955).

, "The Pathology of Presbycusis." Archives of Otology, Vol. 80, p. 369-382, (1964).

Simmons, B. F., "Middle-Ear Muscle Activity at Moderate Sound Levels." Annals of Otology, Vol. 68, p. 1126, (1959).

"Perceptual Theories of Middle-Ear Muscle Function." Annals of Otology, Rhinology, and Laryngology, Vol. 73, p. 724-740, (1964).

Terkildsen, K., and Nielsen, S., "An Electroacoustic Impedance Measuring Bridge for Clinical Use." Archives of otology, Vol. 72, p. 339-346, (1960). 
Troger, J., "Die Schallafnahme durch das aussere." Physiological Zeit, Vol. 31, p. 21-56, (1930).

Tsukamato, H., "Zur Physiologie der Binnenokrmusken." Zeit Biology, Vol. 95, p. 146-154, (1934).

Vital and Health Statistics, National Center for Health Statistics, "Hearing Status and Ear Examination Findings Among Adults, U.S." Series 11:11, (19601962).

Vital and Health Statistics, National Center for Health Statistics, "Hearing Levels of Adults by Age and Sex, U.S." (1960-62).

Webster, A. G., "Acoustic Impedance and the Theory of Horns and of the Phonograph." Proceeds of the National Academy of Science, Vol. 5, p. 275-282, (1919).

Welford, A. T., and Birren, J., Editors, Behavior, Aging, and the Nervous System, Charles Thomas, Springfield, IIIinois, $(1965)$.

Wersall, R., "The Tympanic Muscles and Their Reflexes." Acta-0tolaryngologica, Supplement 139, (1958).

Wever, E. G., and Bray, C. W., "The Tensor Tympani and its Relation to Sound Conduction." Annals of Otology, Rhinology, and Laryngology, Vol. $\frac{46, p}{467-961,}$ $(1937)$.

, "The Stapedius Muscle in Relation to Sound Conduction." Journal of Experimental Psychology, Vol. 31, p. 35-43, (19 42$)$.

, and Lawrence, M., Physiological Acoustics, Princeton University Press, (1954).

, and Vernon, J., "The Control of Sound Transmission by the Middle-Ear Muscles." Annals of otology, Rhinology, and Iaryngology, V01. 65, p. 5-14, (1956).

Wolferman, A., Reconstruction Surgery of the Middle Ear, Grune-Stratton, New York, London, (1970).

Zemlin, W. R., Speech and Hearing Science, Prentice Hall, Englewood Cliffs, New Jersey, (1968).

Zwicker, E., "Uber psychologische and methodische Grundlagen der Lautkeit." Akust Beik, Vol. 1, p. 237258, (1958). 
Zwicker, E., "Subdivision of the Audible Frequency Range into Critical Bands." Journal of the Acoustical Society of America, Vol. 33, p. $\frac{1}{2} 48,(1960)$.

Zwislocki, J., "Acoustic Measurement of the Middle-Ear Function." Annals of Otology, Rhinology, and Laryngology, Vol. $70, \frac{0}{\mathrm{p}} \cdot 599-606,(1961)$. , "An Acoustic Method for Clinical Examination of the Ear." Journal of Speech and Hearing Research, Vol. 6, p. 303-314, $(1963)$.

"Analysis of Some Auditory Characteristics." Handbook of Mathematical Psychology, R. Iuce, R. Bush, and E. Galanter, Editors, Vol. III, p. 1-97, Wiley, New York, (1965). 
APPENDIX A

QUESTIONNAIRE

1. Name:

2. Address:

3. Telephone:

4. Birthdate:

5. Did you notice any significant hearing loss before the age of 50 ?

6. Was your hearing loss of gradual or sudden onset?

7. Have you ever had middle ear infections?

8. Do you suffer from frequent earaches?

9. Have you ever had surgery on your ears?

10. Were you exposed to a noisy environment in your job?

11. Do you include among your hobbies hunting, motorcycle riding, or home machine shop?

12. Were you ever a member of an active military unit?

a) Did your military occupation involve intense noise exposure?

13. Do you consider your general health to be good?

14. How would you rate your hearing - good - fair - poor excellent?

I give my consent to use the information gained from this evaluation for thesis and research purposes. 
APPENDIX B

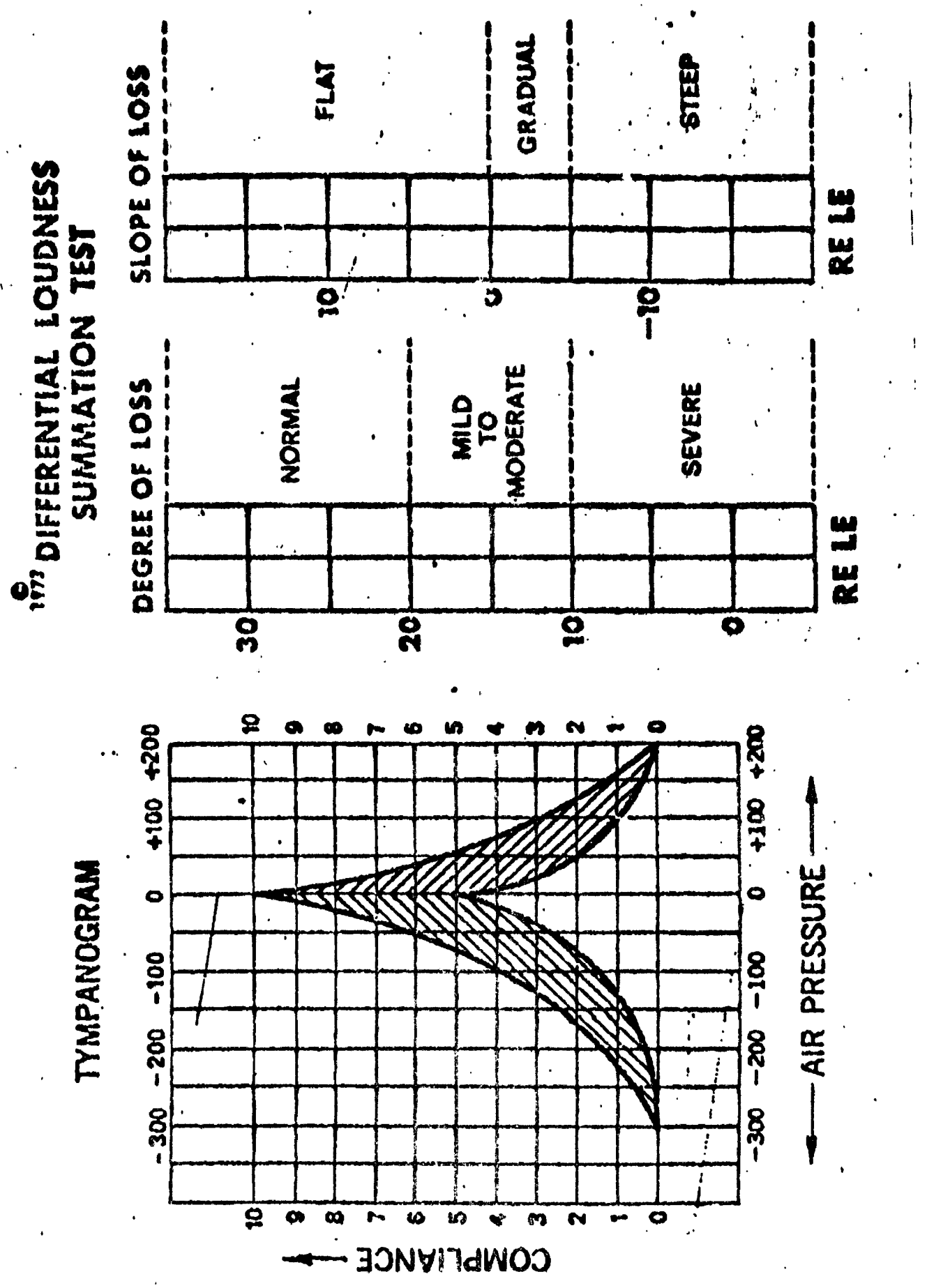

